Key Words:

Environment

Remediation

Retention:

Permanent

\title{
Passive Fluxmeters: Application as a Characterization/Monitoring Tool for Monitored Natural Attenuation of Chlorinated Solvents
}

(A Research Study of the Monitored Natural Attenuation/Enhanced Attenuation for Chlorinated Solvents Technology Alternative Project)

December 7, 2006

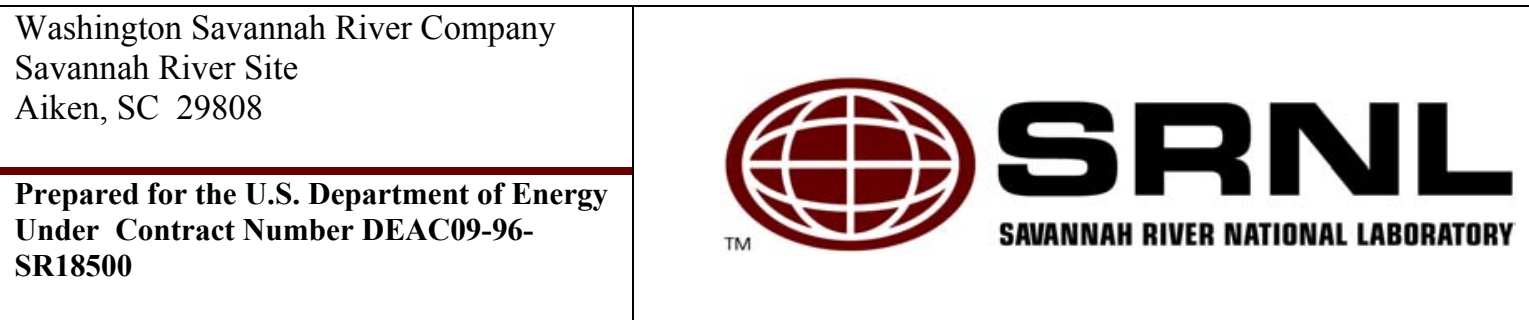




\section{DISCLAIMER}

Preparation of this report was coordinated by Washington Savannah River Company (WSRC) for the United States Department of Energy (US DOE) under Contract No. DE-AC09-96SR18500. Extensive effort was made by the authors to assure the accuracy of the contents and interpretation. However, the USDOE nor WSRC, nor any of their employees makes any warranty, expressed or implied, or assumes any legal liability or responsibility for accuracy, completeness, or usefulness, of any information, apparatus, or product or process disclosed herein or represents that its use will not infringe privately owned rights. Reference herein to any specific commercial product, process, or service by trade name, trademark, name, manufacturer or otherwise does not necessarily constitute or imply endorsement, recommendation, or favoring of same by Washington Savannah River Company or by the United States Government or any agency thereof. The views and opinions of the authors expressed herein do not necessarily state or reflect those of the United States Government or any agency thereof.

Printed in the United States of America

Prepared For

U.S. Department of Energy 
WSRC-STI-2006-00315, Rev. 0

December 7, 2006

Page I- iii of I- vii

Key Words:

Environment

Remediation

Retention:

Permanent

\title{
Passive Fluxmeters: Application as a Characterization/Monitoring Tool for Monitored Natural Attenuation of Chlorinated Solvents
}

\section{(A Research Study of the Monitored Natural Attenuation/Enhanced Attenuation for Chlorinated Solvents Technology Alternative Project)}

\author{
Contributing Researchers: \\ Kirk Hatfield, University of Florida \\ Michael D. Annable, University of Florida \\ Jaehyun Cho, University of Florida \\ Margaret R. Millings, SRNL \\ Introduced by: \\ Karen Vangelas, SRNL \\ Brian B. Looney, SRNL
}

\section{December 7, 2006}

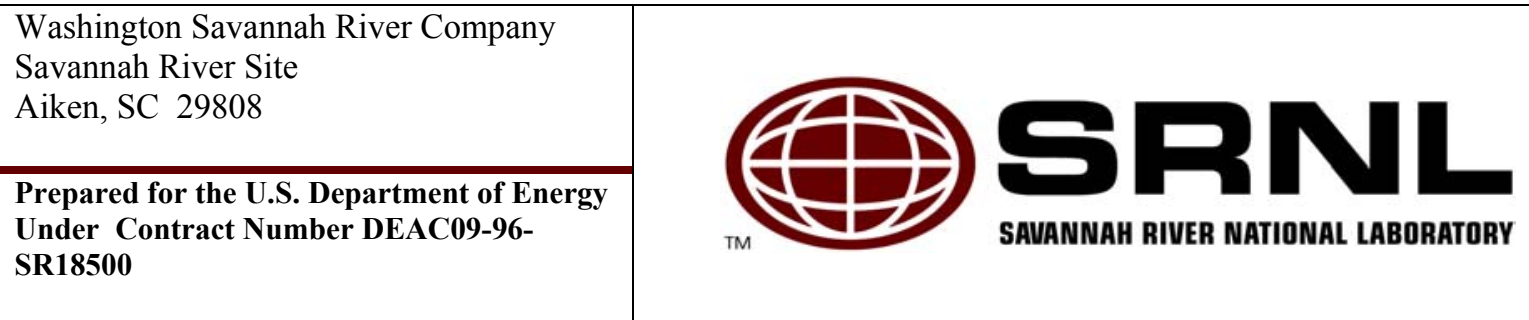




\section{Executive Summary}

The stability of a contaminant plume is a key to initiation of attenuationbased remedies. Measurement of the changes in contaminant flux along a groundwater flow path provides insight into plume stability and contaminant mass balance. Thus characterization and monitoring tools that provide data specifically in terms of mass flux are of great interest. A team of researchers from the University of Florida have developed such a tool, the Passive Fluxmeter, for deployment in groundwater monitoring wells. This tool was developed with support from both the Department of Defense and the Environmental Protection Agency. The results of the research indicate the Passive Fluxmeter provided reasonable measures of local flux for multiple solutes and for water. However, as the researchers noted, unanswered questions remain associated with its use. These questions include upscaling the results into a usable integrated mass flux (the total mass moving through a transect perpendicular to groundwater flow in a given time interval, e.g., $\mathrm{Kg}$ /day), deployment logistics, costs, and reliability/robustness.
Over the past three decades, much progress has been made in the remediation of soil and groundwater contaminated by chlorinated solvents. Yet these pervasive contaminants continue to present a significant challenge to the U.S. Department of Energy (DOE), other federal agencies, and other public and private organizations. The physical and chemical properties of chlorinated solvents make it difficult to rapidly reach the low concentrations typically set as regulatory limits. These technical challenges often result in high costs and long remediation time frames. In 2003, the DOE through the Office of Environmental Management funded a science-based technical project that uses the U.S. Environmental Protection Agency's technical protocol (EPA, 1998) and directives (EPA, 1999) on Monitored Natural Attenuation (MNA) as the foundation on which to introduce supporting concepts and new scientific developments that will support remediation of chlorinated solvents based on natural attenuation processes. This project supports the direction in which many site owners want to move to complete the remediation of their site(s), that being to complete the active treatment portion of the remedial effort and transition into MNA.

The overarching objective of the effort was to examine environmental remedies that are based on natural processes - remedies such as Monitored Natural Attenuation (MNA) or Enhanced Attenuation (EA). The research program did identify several specific opportunities for advances based on: 1) mass

balance as the central framework for attenuation based remedies, 2) scientific advancements and achievements during the past ten years, 3) regulatory and policy development and real-world experience using MNA, and 4) exploration of various ideas for integrating attenuation remedies into a systematic set of "combined remedies" for contaminated sites. These opportunities are summarized herein and are addressed in more detail in referenced project documents and journal articles, as well as in the technical and regulatory documents being developed within the ITRC. 
Three topic areas were identified to facilitate development during this project. Each of these topic areas, 1) mass balance, 2) enhanced attenuation (EA), and 3) innovative characterization and monitoring, was explored in terms of policy, basic and applied research, and the results integrated into a technical approach. Each of these topics is documented in stand alone reports, WSRC-STI-2006-00082, WSRC-STI-2006-00083, and WSRC-STI-2006-00084, respectively. In brief, the mass balance efforts are examining methods and tools to allow a site to be evaluated in terms of a system where the inputs, or loading, are compared to the attenuation and destruction mechanisms and outputs from the system to assess if a plume is growing, stable or shrinking. A key in the mass balance is accounting for the key attenuation processes in the system and determining their rates. EA is an emerging concept that is recognized as a transition step between traditional treatments and MNA. EA facilitates and enables natural attenuation processes to occur in a sustainable manner to allow transition from the primary treatment to MNA. EA technologies are designed to either boost the level of the natural attenuation processes or decrease the loading of contaminants to the system for a period of time sufficient to allow the remedial goals to be met over the long-term. For characterization and monitoring, a phased approach based on documenting the site specific mass balance was developed. Tools and techniques to support the approach included direct measures of the biological processes and various tools to support cost-effective long-term monitoring of systems where the natural attenuation processes are the main treatment remedies. The effort revealed opportunities for integrating attenuation mechanisms into a systematic set of "combined remedies" for contaminated sites.

An important portion of this project was a suite of 14 research studies that supported the development of the three topic areas. A research study could support one or more of these three topic areas, with one area identified as the primary target. The following report documents the results of field validation of the use of passive fluxmeters (PFMs) to provide direct in situ measurements of both cumulative water and multiple solute fluxes. This effort was led by Kirk Hatfield and Michael Annable of the University of Florida. This study supports the topic area(s) of mass balance and characterization and monitoring. The objective of the study was to refine and deploy a tool to measure flux more directly than traditional methods and to develop a field-based protocol for determining contaminant loading, contaminant attenuation, and assimilative capacity using spatially distributed flux measurements of target contaminants. The passive fluxmeter is a down-hole device that is deployed for an extended time and then retrieved and analyzed to directly assess the in situ cumulative water and dissolved contaminant fluxes in the vicinity of the well. By spatially integrating the results from transects of PFMs, estimates of integrated mass discharge/mass flux can be calculated and inputted into mass balance calculations for an overall groundwater plume. The PFMs work on a simple concept. A sorbing material is placed within the PFM and impregnated with soluble resident tracers. As contaminated groundwater passively flows through the PFMs the contaminants are sorbed to the sorbent material within the PFM and the soluble resident tracers are leached at a rate proportional to groundwater flux. 
WSRC-STI-2006-00315, Rev. 0

December 7, 2006

Page I- vi of I- vii

As the MNA/EA project's Technical Working Group (TWG) evaluated the importance of mass balance in determining if an attenuation based remedy would be appropriate for a site, they identified the flux of contaminants as an important measure. Key to implementing attenuation based remedies is that the plume be stable or shrinking. Flux measurements when normalized to a unit area provide a rate than can be inputted into models to evaluate plume stability and sustainability. The TWG concluded that flux measurements can be valuable information to support decisions related to transitioning from one technology to another (typically from a source removal and/or treatment to an interdiction and active treatment and from an active treatment to an attenuation based treatment). The TWG also concluded that point concentration measurements will continue to be the metric for success in site closure.

Overall, the TWG was supportive of this work in that it advances the measurement and use of mass flux. However, TWG members raised several points that warrant further investigation. First, the technique is a point measurement that adds "time" to the equation (e.g. averages over time). The tool has some of the same traditional issues with measurement in a well (e.g. screen lengths, adequate groundwater velocity etc.) that other downhole tools have. Secondly, this method should be compared to alternative methods for calculating flux (e.g., simple methods to combine traditional estimates of flow and concentrations, pump tests, etc.) to evaluate relative strengths and weaknesses. Third, the impact of the subsurface microbial community on the soluble resident tracers is unknown and the subsequent impact on results. Finally, the TWG recommended additional study of the reproducibility, reliability and robustness of the PFM equipment and method and a more complete evaluation of costs. 
WSRC-STI-2006-00315, Rev. 0

December 7, 2006

\section{References for Introduction}

\section{Page I- vii of I- vii}

EPA, 1998. Technical Protocol for Evaluating Natural Attenuation of Chlorinated Solvents in Groundwater, EPA/600/R-98/128. Washington DC. September 1998.

EPA, 1999. Use of Monitored Natural Attenuation at Superfund, RCRA Corrective Action and Underground Storage Tank Sites, OSWER Directive 9200.4-17P. Washington DC. April 21, 1999.

WSRC-STI-2006-00082, 2006. Mass Balance: A Key to Advancing Monitored and Enhanced Attenuation for Chlorinated Solvents. Washington Savannah River Company, Aiken, SC, 29808. June 2006. Available at www.osti.gov.

WSRC-STI-2006-00083, 2006. Enhanced Attenuation: A Reference Guide on Approaches to Increase the Natural Treatment Capacity of a System, Revision 1. Washington Savannah River Company, Aiken, SC, 29808. August 2006. Available at www.osti.gov.

WSRC-STI-2006-00084, 2006. Characterization and Monitoring of Natural Attenuation of Chlorinated Solvents in Ground Water: A Systems Approach, Revision 1. Washington Savannah River Company, Aiken, SC, 29808. August 2006. Available at www.osti.gov. 
WSRC-STI-2006-00315, Rev. 0

December 7, 2006

Page i of ix

\title{
Passive Fluxmeters: Application as a Characterization/Monitoring Tool for Monitored Natural Attenuation of Chlorinated Solvents
}

\author{
Kirk Hatfield, Michael D. Annable, and Jaehyun Cho \\ University of Florida
}

Margaret Millings

Savannah River National Laboratory

October 2006 


\section{Table of Contents}

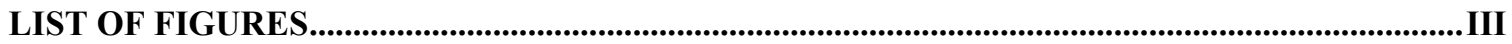

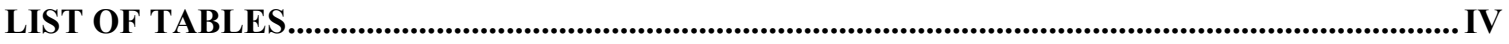

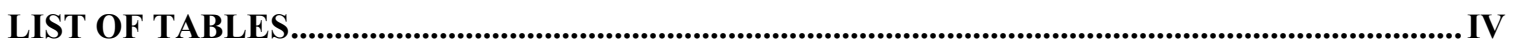

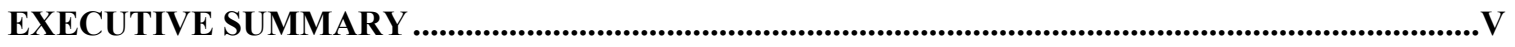

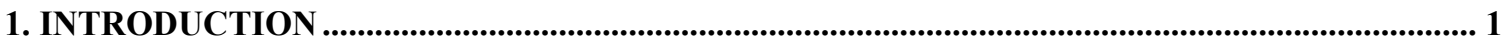

1.1 Monitored Natural and Enhanced Attenuation And Mass FluX........................................ 1

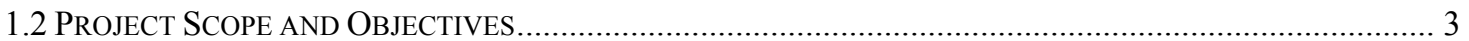

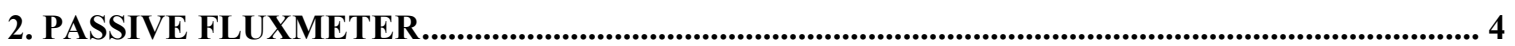

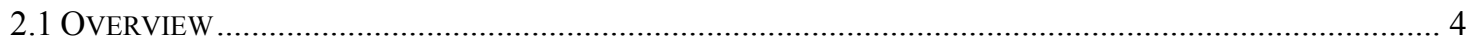

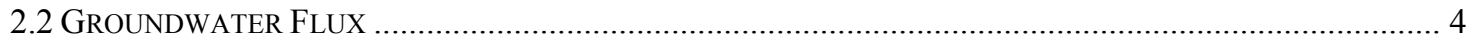

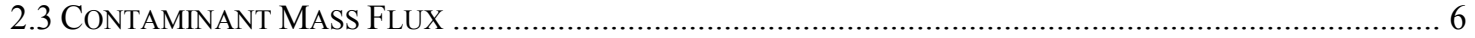

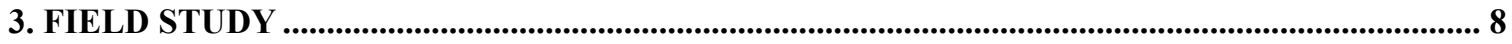

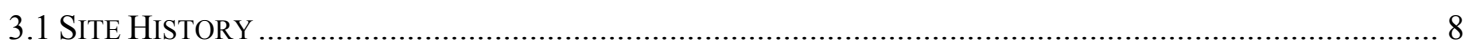

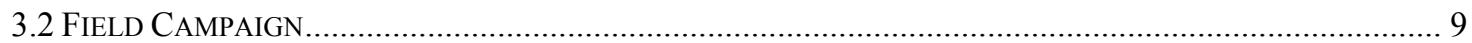

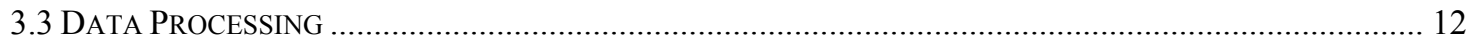

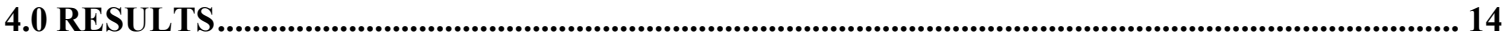

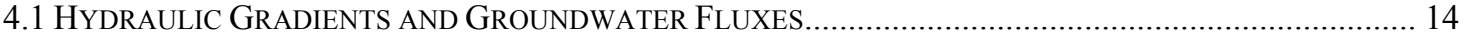

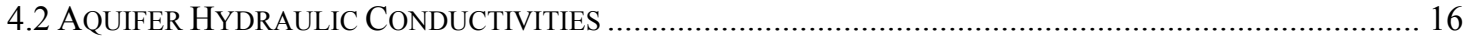

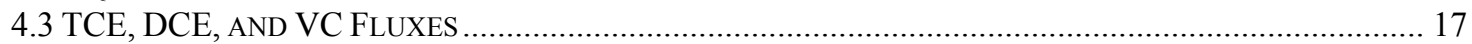

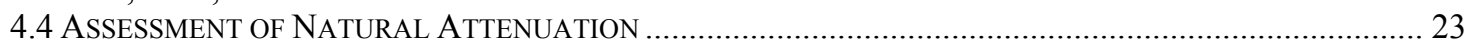

5.0 CONCLUSIONS AND RECOMMENDATIONS............................................................................... 27

6.0 REFERENCES ........................................................................................................................... 29 


\section{List of Figures}

Figure 2.1. Schematic of a PFM comprised of a permeable sock filled with a selected sorbent......

Figure 2.2. PFM cross-sections (A): tracer distribution after exposure to groundwater flow field, (B): contaminant distribution after exposure to groundwater flow field. ......... 7 Figure 3.1. Test bed encompassing Twin Lakes and the C-Area Burning/Rubble Pit (Bills et al. 2000).

Figure 3.2. Network of 14 wells used for PFM in the test bed encompassing Twin Lakes.

Figure 3.3. Data processing flow chart used to generate final results (blue) from raw data (red).......

Figure 4.1. Second-order polynomial fit to groundwater elevations measured near Twin Lakes in September 2005. Distance down-gradient from well CRP41 is positive.

Figure 4.2. PFM measured groundwater specific discharge at each well during each of the three deployments and the simple arithmetic average. Well numbers correspond to those presented in Table 3.1 and matched with labels previously specified. ................... 16

Figure 4.3. TCE and DCE Flux histograms............................................................. 18

Figure 4.4. Depth variations in measured TCE and DCE fluxes at well CRP41A and CRP41B.

Figure 4.5. TCE fluxes measured in the direction of groundwater flow from three PFM deployment durations....................................................................................... 20

Figure 4.7. 189-day average molar fluxes for TCE, DCE, and their sum. .................... 21

Figure 4.8. Flux-averaged concentrations of TCE and DCE from PFMs compared to groundwater concentrations averaged from three sampling events............................... 23

Figure 4.9. First-order modeling of TCE and DCE degradation near Twin Lakes. ........ 26 
WSRC-STI-2006-00315, Rev. 0

December 7, 2006

\section{List of Tables}

Page iv of ix

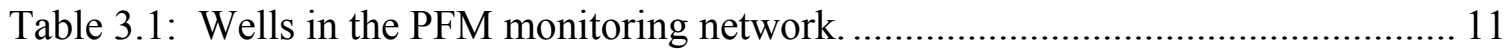

Table 4.1: Statistics of PFM measured groundwater specific discharge. ...................... 15

Table 4.2. Statistics on PFM measured aquifer conductivities...................................... 17

Table 4.3. Statistics of contaminant fluxes from the three PFM deployments................ 18 


\section{WSRC-STI-2006-00315, Rev. 0 \\ December 7, 2006 \\ Page v of ix}

\section{Executive Summary}

There is a growing consensus in the literature that measured or estimated contaminant mass flux $J$ $\left[\mathrm{M} / \mathrm{L}^{2} / \mathrm{T}\right]$ or contaminant mass discharge $M_{Q}$ can be used to generate robust estimates of natural and enhanced attenuation, and they can be used to characterize subsurface assimilative capacity (Borden et al. 1997; USEPA, 1998; and Bockelmann et al. 2003; Basu 2005). Contaminant mass flux $J$ is generally defined as the mass of contaminant passing through a unit area per unit time, while the integrated mass flux or contaminant mass discharge is the spatial integration of the contaminant flux over a control plane.

This report presents results of a research project in which passive fluxmeters (PFMs) are used to measure changes of chlorinated ethene fluxes along the axis of a groundwater contaminant plume. A PFM is a down-hole device that operates passively to provide direct, in situ, cumulative measures of both local water and dissolved contaminant fluxes. A transect of PFMs provides information that when spatially integrated generates estimates of contaminant mass discharge. Multiple PFM transects located down-gradient from a source area can be used to estimate spatial changes in contaminant mass discharge which are needed to calculate contaminant mass balances and characterize the intensity of natural attenuation (Bockelmann et al., 2003).

The objectives of this research were:

1) demonstrate an innovative technology for direct in situ measurement of cumulative water and multiple solute fluxes in groundwater,

2) develop a field-based protocol for determining contaminant loading, contaminant attenuation, and assimilative capacity using spatially distributed flux measurements of target contaminants (see Figure 3.3), and

3) advance the science and understanding of natural attenuation using measured fluxes.

The research plan included subsurface flux monitoring in a test-bed at the Savannah River Site (SRS) located immediately down-gradient of the C-Area Burning/Rubble Pit (CBRP). As a result of the disposal practices at the CBRP during the 1960-70's, a dissolved trichloroethylene (TCE) plume developed in the underlying aquifer extending approximately $1200 \mathrm{~m}$ from the CBRP to Fourmile Branch and an unnamed tributary that included the Twin Lakes. The plume width was 
WSRC-STI-2006-00315, Rev. 0

December 7, 2006

Page vi of ix

previously estimated at $18 \mathrm{~m}$. Prior investigations found TCE above the maximum contaminant limits in surface waters of Twin Lakes but not in Fourmile Branch. Near the CBRP, the bulk groundwater was aerobic shifting toward reducing conditions in the swampy outcrop environment of Twin Lakes. It was here that both cis-1,2-dichloroethylene (DCE) and vinyl chloride (VC) were detected, which suggested TCE was undergoing reductive dechlorination.

Flux monitoring of the TCE/DCE/VC plume was confined to 14 wells located within the Twin Lakes outcrop environment. This area was chosen because the ecological and geochemical environments that the contaminant plume flows through change as one moves down the centerline of the plume from the source to the discharge point providing an excellent setting to evaluate the robustness of the PFMs for measuring contaminant fluxes in the plume.

Silver-impregnated-granular-activated carbon was used as a sorbent inside each fluxmeter. The purpose of the sorbent was to intercept and retain dissolved TCE, DCE, and VC from groundwater flowing passively through the well and then through the fluxmeter. The sorbent was also impregnated with known amounts of one or more fluid soluble resident tracers (various branched alcohols). These tracers were leached from the sorbent at rates proportional to groundwater flux. When PFMs were retrieved from the field, the sorbent was sampled and analyzed to quantify the contaminant mass intercepted and residual masses of multiple resident tracers. The former was used to quantify contaminant flux and the latter to determine groundwater flux.

Flux monitoring at the Twin Lakes test-bed was conducted over an 18 month period between the months of January 2005 to July 2006. The network of 14 wells covered the last $530 \mathrm{~m}$ or $45 \%$ of the leading longitudinal extent of the chlorinated solvent plume originating from the CBRP. PFMs were deployed for three durations of 8, 42, and 139 days. Water levels were measured and groundwater samples were collected from each well just before the PFMs were installed. Immediately following the above stated exposure periods to ambient groundwater flow conditions, each PFM was retrieved and the sorbent sampled. Three to four samples were collected from each fluxmeter. Each sample provided depth-integrated flux measurement corresponding to an $\sim 15 \mathrm{~cm}$ depth interval and three to four samples per fluxmeter provided data over the totaling the length of well screen $(\sim 45.7$ to $\sim 61 \mathrm{~cm})$. 
WSRC-STI-2006-00315, Rev. 0

December 7, 2006

Page vii of ix

Water levels measured on three separate occasions within the 18 month field effort produced similar groundwater elevation profiles; consequently, the horizontal hydraulic gradient differed between wells but not significantly over experiment duration. Groundwater fluxes were determined as function of depth at each of the 14 well locations. Due to minor temporal variations in the local horizontal hydraulic gradients, the average ground water flux for the site ranged 2.1 to $2.3 \mathrm{~cm} / \mathrm{d}$ between the three deployments. In other words, consistent site-wide averages were obtained even though durations of flux monitoring varied by an order of magnitude. Between wells, the depth-average specific discharge ranged between 0.6 to $7.4 \mathrm{~cm} / \mathrm{d}$; this corresponded to pore water velocities ranging from 2-30 cm/d using an effective porosity of $25 \%$. At most wells the depth-averaged local estimate of groundwater specific discharge was consistent regardless of PFM deployment period. The only exceptions were wells CRP40B and perhaps CRP44B; here, measurement variations were greater.

PFM measured groundwater specific discharges and the above described calculated local gradients were used to determine local aquifer conductivities at each well using Darcy's Law. Measured conductivities varied between wells; however, at any given well results were similar between the different PFM deployment periods. Absolute conductivity values range 0.3 to 7.9 $\mathrm{m} / \mathrm{d}$ over all well and all depths. Arithmetic averages compared closely to the slug test estimates (Flach et al. 1999). A histogram plot of conductivities measured from all wells and all depths indicated the chosen increment of depth sampling $(15 \mathrm{~cm})$ was sufficiently small to reveal a conductivity distribution that was positively skewed (i.e., possibly lognormal). Most wells produced consistent determinations of water flux and in turn credible estimates of local aquifer conductivities under quasi-steady hydraulic conditions; hence, it was surmised PFMs installations were consistent and properly installed.

Measurable TCE and DCE fluxes were found in several wells. VC fluxes, however, were quite low $\left(0.25 \mathrm{mg} / \mathrm{m}^{2} / \mathrm{d}\right)$, measured in CRP 44B alone, and then only during the third deployment. After integrating results from three deployments, the 189-day average fluxes for TCE and DCE were 3-4 and 1-2 mg/m $/ \mathrm{m}^{2} / \mathrm{d}$ respectively. Peak TCE mass flows occurred at well CRP41 and then decreased rapidly within 200 meters in the direction of horizontal groundwater flow. These fluxes were measured over consistent depth intervals of 1.6-4 $\mathrm{m}$ below ground surface and from wells horizontally distributed over a distance of $400 \mathrm{~m}$; thus, it was surmised dispersion, degradation, and possibly volatilization were effecting contaminant attenuation within this thin vertical section of aquifer. Further down-gradient from CRP41A and CRP41B, DCE fluxes 
WSRC-STI-2006-00315, Rev. 0

December 7, 2006

Page viii of ix

increased while TCE decreased significantly. This increase in DCE was due to TCE degradation; however, the rate of increase was less than predicted if DCE were conserved. Plots of TCE and DCE molar fluxes, and their sum revealed that DCE was attenuated at rates similar to TCE; however, at the down-gradient end of the sampling network, the rate of DCE attenuation appeared to stall. Using contaminant fluxes from CRP41 as a reference, molar attenuation was approximately $99 \%$ for TCE and $85 \%$ for DCE.

Given the extended duration of PFM deployments, the potential for TCE and DCE degradation on the PFM sorbent was a concern. Following Basu et al. (2006), flux-averaged concentrations for TCE and DCE were derived from PFM data and then compared to measured concentrations from sampled well water. The comparison was generally favorable; although, to be conclusive additional study was recommended.

Measured contaminant fluxes were used to quantify subsurface contaminant loading and the assimilative capacity of the aquifer within the sampling network. It was assumed the 14 monitoring wells were completed in the same continuous groundwater flow system. Thus, the fate of contaminants measured in up-gradient wells was assumed to be appropriately depicted in wells down-gradient. Analyses also assumed measured fluxes at wells CRP41A and CRP41B could be taken as representative TCE and DCE loads to the aquifer underlying Twin Lakes.

Measured contaminant loads (expressed in micromoles) ranged from $69-130 \mu \mathrm{M} / \mathrm{m}^{2} / \mathrm{d}$ for TCE and 11-12 uM/m²/d for DCE and wells CRP41A and CRP41B. Resultant 189-day weighted averages were 123 and $11 \mu \mathrm{M} / \mathrm{m}^{2} / \mathrm{d}$. Fluxes measured in wells constituting a transverse transect located at the down-gradient end of the monitoring network (.i.e., wells CRP44A, CRP44B, CRP49A, and CRP 49B) were taken to represent TCE, DCE, and VC mass discharges not attenuated within boundaries of the test site. Here residual chlorinated ethane fluxes were 0-2 $\mu \mathrm{M} / \mathrm{m}^{2} / \mathrm{d}$ TCE, $14-29 \mu \mathrm{M} / \mathrm{m}^{2} / \mathrm{d}$ DCE and $1 \mu \mathrm{M} / \mathrm{m}^{2} / \mathrm{d}$ VC. The corresponding 189 -day average fluxes were $0.5,1.0$, and $20 \mu \mathrm{M} / \mathrm{m}^{2} / \mathrm{d}$ for TCE, VC, and DCE respectively.

The composite assimilative capacity of the aquifer to degrade TCE and associated daughter products were expressed in terms chloride equivalents or the total moles of free chloride produced when TCE, DCE, and VC were completely degraded. Using 189-day average fluxes for TCE, DCE, and VC entering and leaving the sampling network, the assimilative capacity of the aquifer 
WSRC-STI-2006-00315, Rev. 0

December 7, 2006

Page ix of ix

was estimated at $349 \mu \mathrm{M} / \mathrm{m}^{2} / \mathrm{d}$ as chloride equivalents. This resulted in a level of attenuation that was approximately $89 \%$ complete.

Modeling was conducted to characterize the rates of TCE and DCE attenuation. Coupled fluxbased reactive transport equations were presented and solved to reproduce observed fluxes at monitoring wells. Best-fit values of first order degradation parameters $\lambda_{T C E}$ and $\lambda_{D C E}$ for TCE and DCE for were 0.48 and $0.47 \mathrm{yr}^{-1}$ respectively. Values of calibrated decay parameters reflected 'effective' or 'apparent' estimates that were well within the range of values (0.1-1 $\left.\mathrm{yr}^{-1}\right)$ reported in the literature (Weidemier et al. 1999). The nature of TCE and DCE degradation was not discerned here, but likely included both aerobic and anaerobic pathways (Basu et al. 2006; Sing et al. 2004; and Davis et al. 2002). The model produced reasonable simulations of TCE and DCE fluxes at most well locations except at the down-gradient end of the sampling network. Here it appeared the model over estimated DCE attenuation. Because low VC fluxes were measured here and nowhere else, this could mean that both DCE and VC attenuation had stalled. 


\subsection{Introduction}

\subsection{Monitored Natural and Enhanced Attenuation and Mass Flux}

There is a growing consensus in the literature that measured or estimated contaminant mass flux $J$ $\left[\mathrm{M} / \mathrm{L}^{2} / \mathrm{T}\right]$ or contaminant mass discharge $M_{Q}$ can be used to generate robust estimates of natural and enhanced attenuation, and they can be used to characterize subsurface assimilative capacity (Borden et al. 1997; USEPA, 1998; and Bockelmann et al. 2003; Basu 2006). Contaminant mass flux $J$ is generally defined as the mass of contaminant passing through a unit area per unit time. Assuming convective transport is dominant. Then,

$$
J_{C}=q_{O} C_{F}
$$

where $\mathrm{q}_{\mathrm{o}}$ is specific discharge, $[\mathrm{L} / \mathrm{T}]$; and $\mathrm{C}_{\mathrm{F}}$ is the flux-averaged contaminant concentration in

the groundwater, $\left[\mathrm{M} / \mathrm{L}^{3}\right]$. The integrated mass flux or contaminant mass discharge $M_{Q}$ is the spatial integration of the contaminant flux over a control plane, $A_{S}$; thus,

$$
M_{Q}=\int_{A_{S}} J_{C} d A
$$

where $M_{Q}$ is the contaminant mass discharge, $[\mathrm{M} / \mathrm{T}] ; d A$ represents an elemental area, $\left[\mathrm{L}^{2}\right]$; and $\mathrm{A}_{\mathrm{s}}$ is the source area or the area of the control plane orthogonal to groundwater flow $\left[\mathrm{L}^{2}\right]$. Accurate determination of subsurface solute mass flows is difficult using concentration-based field data and typical methods of estimating groundwater fluxes, because spatial variations in both concentrations and groundwater flows induce mass flow variations that range orders of magnitude. Notwithstanding this variability, hydrologists typically approximate solute mass flows using calculated (i.e., not measured) groundwater fluxes and depth-averaged concentrations gathered from wells. This approach can obscure depth variations in flux which can propagate errors in estimated contaminant loads and contaminant attenuation from which erroneous assessments of system assimilative capacities may be derived. 
WSRC-STI-2006-00315, Rev. 0

December 7, 2006

Page 2 of 31

Currently, three methods exist to estimate integrated contaminant mass flux or mass discharge from field measurements. The first assumes mass discharge estimates can be derived from spatially integrating the product of measured local flux-averaged contaminant concentration, $\mathrm{C}_{\mathrm{F}}$ and indirect estimates of water flux. Point-wise estimates of $\mathrm{C}_{\mathrm{F}}$ are obtained directly from sampling transects of single or multilevel monitoring wells. Water fluxes, however, are determined indirectly, that is they are assumed or calculated at locations of each sampling point. Finally, an integration or spatial averaging of point estimates is performed to quantify contaminant flow over the entire transect. Kuebert and Finkel (2006) describe six variations this method, while Borden et al. (1997), King et al. (1999), and Kao and Wang (2001) present results of field demonstrations.

Holder, et al., (1998), Schwarz et al. (1998), Teutsch et al. (2000), and Bockelmann et al. (2001 and 2003) describe the development and evaluation of a second method or the integral groundwater investigation method (IGIM). This technique directly measures $M_{Q}$, and it involves one or more wells pumped at constant flow rates to provide partial or complete capture of the dissolved plume. The contaminant concentration histories monitored at the wells are interpreted to estimate contaminant mass flow from a portion of the control plane (vertical cross-section) of the plume. The cross-sectional area of aquifer interrogated, $A_{s}$, is calculated from the well flow rate and the ambient groundwater flux, which may be measured, calculated, or assumed. The method provides limited information on the spatial distribution of contaminant fluxes; although mass discharge estimates may reflect less uncertainty because spatial integration/interpolation of point data is not performed. Usually, the IGIM is performed with one well; although, BayerRaich et al. (2006) describe a multi-well IGIM to infer mass flows and natural attenuation rates. Contaminant flux values derived from single applications of the above two methods represent short-term evaluations that reflect current conditions and not long-term trends.

Hatfield et al. (2002 and 2004) introduced a third method known as the passive fluxmeter (PFM). This is a down-hole device that operates passively and provides direct, in situ, cumulative local measures of both water and dissolved contaminant fluxes. Cumulative flux monitoring incorporates day-to-day fluctuations in flow and contaminant concentration and can therefore generate measures that reflect long-term transport conditions. Annable et al. (2005) present evidence of PFM validation in the field, Basu et al. (2006) recently demonstrate their utility in 
WSRC-STI-2006-00315, Rev. 0

December 7, 2006

Page 3 of 31

site characterization, Campbell et al. (2006) and Klammler et al. (2006a) introduce various PFM designs for measuring both the magnitude and direction of fluxes.

Like the first method described above, a transect of PFMs provides information that must be spatially integrated to estimate contaminant mass discharge. However, this discharge estimate is generally more accurate than alternative estimates derived under the first method (Kuebert and Finkel 2006). Regardless of method, integrated fluxes from more than one transect located downgradient from a source zone can be used to quantify natural attenuation and contaminant mass balances (Bockelmann et al., 2003). Thus far, the PFM has not been evaluated as a tool to monitor multiple organic/inorganic solutes fluxes or to support characterization and monitoring at sites where monitored natural attenuation/enhanced attenuation (MNA/EA) is the focus.

\subsection{Project Scope and Objectives}

Because PFMs could be used to generate field estimates of integrated contaminant fluxes, it was relevant to determine if PFMs possess significant utility as a tool for conducting MNA and assessing the potential for EA. This report presents results of a field effort conducted at the Twin Lakes site of the Department of Energy's Savannah River Site located in Aiken, South Carolina. The scope of this research effort was to evaluate the effectiveness of PFMs for monitoring the simultaneous natural attenuation of multiple chlorinated ethenes. The specific research objectives were to:

1) demonstrate an innovative technology for direct in situ measurement of cumulative water and multiple solute fluxes in groundwater,

2) develop a field-based protocol for determining contaminant loading, contaminant attenuation, and assimilative capacity using spatially distributed flux measurements of target contaminants, and

3) advance the science and understanding of natural attenuation using measured fluxes. 


\subsection{Passive Fluxmeter}

\subsection{Overview}

The PFM is a self-contained permeable unit that is inserted into a well or boring such that it allows groundwater to flow passively through it (See Figure 2.1). The interior composition of the meter is a matrix of hydrophobic and/or hydrophilic permeable sorbents that retain dissolved organic and/or inorganic contaminants present in fluid intercepted by the unit. The sorbent matrix is also impregnated with known amounts of one or more fluid soluble resident tracers. These tracers are leached from the PFM at rates proportional to groundwater flux.

After a specified period of exposure to groundwater flow, the PFM is removed from the well. The sorbent is then carefully extracted to quantify the mass of all contaminants intercepted by the PFM and the residual masses of all resident tracers. The contaminants masses are used to calculate cumulative time-averaged contaminant mass fluxes, while residual resident tracer masses are used to calculate cumulative time-average groundwater flux (Hatfield et al. 2004). Depth variations of both groundwater and contaminant fluxes can be measured in an aquifer from a single PFM by vertically segmenting the exposed sorbent packing, and analyzing for resident tracers and contaminants (Annable et al. 2005; Basu et al. 2006; and Klammler et al. 2006b). Thus, at any specific well depth, an extraction from locally exposed sorbent yields the mass of resident tracer remaining and the mass of contaminant intercepted. Note that multiple tracers with a range of partitioning coefficients are typically used to determine variability in groundwater flow with depth.

\subsection{Groundwater Flux}

As indicated above, resident tracers are used to estimate total groundwater flux. As groundwater flows through the PFM, soluble tracers are eluted from the sorbent matrix and displaced from the PFM. Figure 2.2 illustrates two hypothetical cross-sections of a meter configured as a circular column (such as one installed in a monitoring well). Cross-section-A reveals a single resident tracer displaced to the right and displaced from the section in a manner consistent with the assumption that fluid streamlines are parallel to the general direction of groundwater flow (Klammler et al. 2006b). The residual mass of resident tracer retained within the PFM crosssection is measured and used to quantify cumulative water flux. 
WSRC-STI-2006-00315, Rev. 0

December 7, 2006

Page 5 of 31

Assuming reversible, linear and instantaneous resident tracer partitioning between the sorbent and groundwater, the cumulative volume of groundwater intercepted by the PFM, at a specified well depth is obtained iteratively using the following equation:

$$
\xi=\left\{1-\left[\operatorname{Sin}\left(\frac{\pi M_{R}}{2}+\xi \sqrt{1-\xi^{2}}\right)\right]^{2}\right\}^{1 / 2}
$$

where $M_{R}$ is the relative mass of tracer retained in the PFM sorbent at the particular well depth and $\xi$ is the dimensionless cumulative volume of groundwater intercepted by the PFM (Annable 2005; and Hatfield et al 2004, 2002a, 2002b).

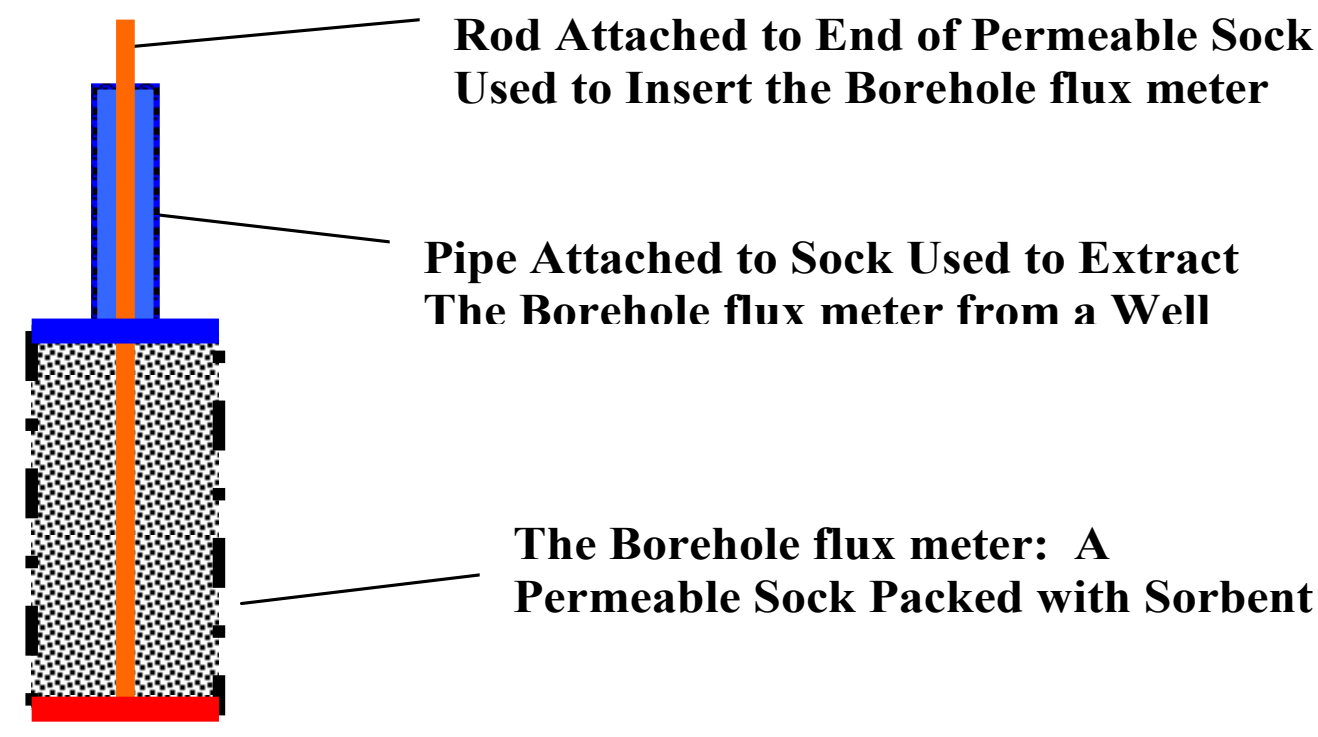

Figure 2.1. Schematic of a PFM comprised of a permeable sock filled with a selected sorbent

The groundwater flux, q [L/T](e.g., m/day), through the sorbent is calculated using:

$$
q=\frac{2 r \theta R_{d} \xi}{t}
$$


WSRC-STI-2006-00315, Rev. 0

December 7, 2006

Page 6 of 31

where $r$ is the radius of the PFM cylinder; $\theta$, is the water content of the sorbent; $R_{d}$ is the retardation factor of the resident tracer on the sorbent; and $t$ is the sampling duration. Since in most field applications, groundwater flux is unknown, multiple resident tracers are typically used to represent a broad range of tracer retardation factors. Likewise, multiple tracers provide for PFMs designed for both long- and short-term sampling durations.

As indicated above, $q$, is the specific discharge of groundwater flowing through the sorbent; however, the flux of interest is the ambient specific discharge of groundwater, $q_{O}$. The two discharges are linearly related.

$$
q=\alpha q_{O}
$$

where $\alpha$ is a factor, calculated from the geometry of the well and the estimated permeabilities of the aquifer, the well screen, the well packing, and the sorbent (Klammler et al., 2006b).

\subsection{Contaminant Mass Flux}

The distribution of contaminant intercepted and retained on the PFM sorbent after exposure to groundwater flow field is illustrated in cross-section-B of Figure 2.2. The contaminant mass retained is used to estimate the local contaminant flux. The measured flux is valid over the dimensions of porous medium contributing flow to the PFM. For example, a PFM designed to sample the entire vertical depth of an aquifer could be used to characterize horizontal groundwater and contaminant fluxes continuously over the vertical extent of an aquifer. The timeaveraged convective contaminant mass flux from a finite sampling duration is calculated from mass of contaminant intercepted by the PFM using the following equation (Hatfield et al., 2004):

$$
J_{C}=\frac{1.67 m_{C}}{\alpha \pi r b t}
$$

where $J_{c}\left[\mathrm{M} /\left(\mathrm{L}^{2} \mathrm{~T}\right)\right]$ is the time-averaged ambient convective contaminant mass flux, $m_{c}[\mathrm{M}]$ is the mass of contaminant sorbed, $b[\mathrm{~L}]$ is the length of sorptive matrix sampled or the vertical thickness of aquifer interval interrogated, and $t[T]$ is the duration of the measurement. The flux average concentration $C_{F}\left[M / L^{3}\right]$ is determined $C_{F}=\left[J_{c} / q\right]$. 


\section{PFM Concepts}

\section{Water Flux}

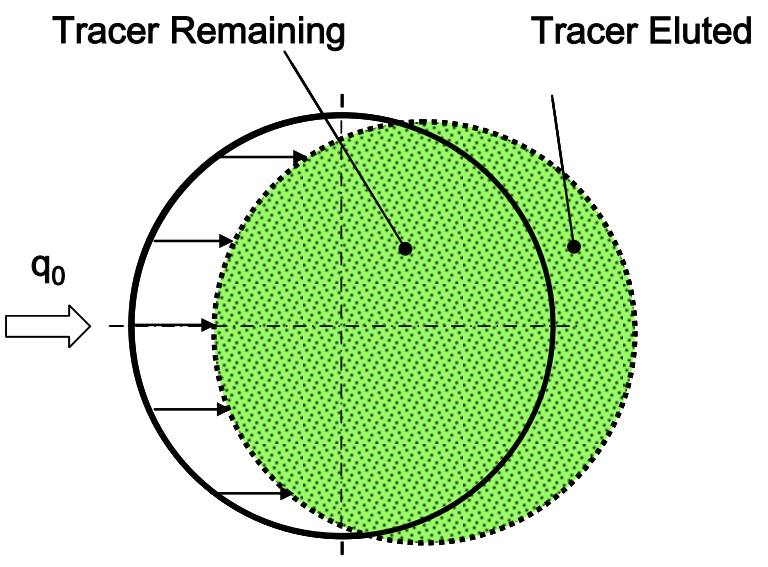

A
Contaminant Flux

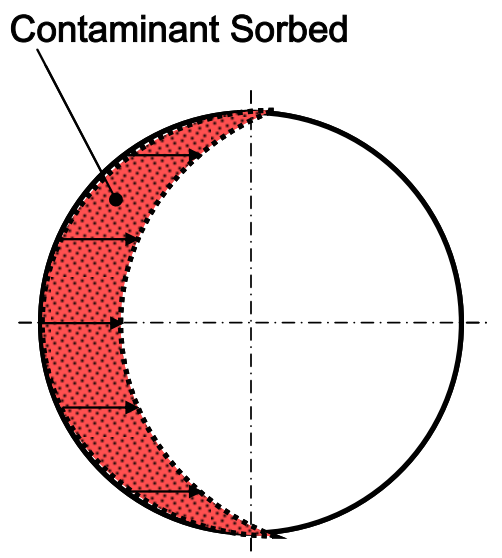

B

Figure 2.2. PFM cross-sections (A): tracer distribution after exposure to groundwater flow field, (B): contaminant distribution after exposure to groundwater flow field.

Multiple PFMs located in a transect perpendicular to the mean direction of groundwater flow can be used to produce estimates of contaminant mass discharge (integrated flux) which is equivalent to the strength of the plume, if the transect encompasses the transverse extent of the dissolved plume, or the source strength if flux integration is performed across a "control plane" located immediately down gradient of the source zone. 


\subsection{Field Study}

\subsection{Site History}

The field site exists within the boundaries of the Department of Energy's Savannah River Site (SRS) which encompasses approximately 310 square miles in South Carolina, adjacent to the Savannah River. Geographically it lies within the Atlantic Coastal Plain, a southeast-dipping wedge of unconsolidated and semi-consolidated sediment that extends from its contact with the Piedmont Province at the Fall Line to the edge of the continental shelf. Groundwater flow in the upper aquifers at the SRS is driven by recharge, with streams intercepting flow from areas of higher groundwater elevations. Nearly all recharge within the study area discharges to streams (Aadland et al., 1991; 1995).

Subsurface flux monitoring was conducted in a test-bed at the SRS located immediately downgradient of the C-Area Burning/Rubble Pit (CBRP). The CBRP was constructed in the early 1960s for use as a burning pit. It was approximately $7.6 \mathrm{~m}$ wide by $33 \mathrm{~m}$ in length with depth ranging from 2.4 to $3.7 \mathrm{~m}$. Materials disposed into the pit during operations included organic solvents, waste oils, paper, plastics, and rubber. These materials were burned periodically to reduce the overall waste volume in the pit. After 1973, the pit was used to dispose of inert rubble. Characterization activities indicated a small volume of DNAPL, primarily trichloroethylene (TCE), in the vadose zone near the pit. An active soil vapor extraction system was used to remediate the source; thus, eliminating TCE loading to the underlying aquifer.

As a result of the disposal practices at the CBRP there is a dissolved TCE plume in the underlying aquifer (see Figure 3.1). The plume extends approximately $1200 \mathrm{~m}$ from the CBRP to Fourmile Branch and an unnamed tributary that includes the Twin Lakes. The plume is approximately 18 $m$ in width. The Twin Lakes are two former ponds that have been breached. At present they are mostly a swampy area that periodically retains water during periods of heavy rain; thus, they represent zones of groundwater discharge. TCE is found above the maximum contaminant limits in surface waters of the Twin Lakes but not in Fourmile Branch. Near the source, the bulk groundwater is aerobic shifting toward reducing conditions in the swampy outcrop environment of Twin Lakes. It is here that both cis-1,2-dichloroethylene (DCE) and vinyl chloride (VC) are detected, which suggests TCE is undergoing reductive dechlorination. 
Flux monitoring of the TCE/DCE/VC plume was confined to wells located within the Twin Lakes outcrop environment. This area was chosen because contaminants migrate through ecological and geochemical environments that change along the centerline of the plume from the source to the discharge point. This provides an excellent setting to evaluate the robustness of the PFMs to estimate contaminant fluxes along the length of a plume in regions and at contaminant concentrations typical for natural attenuation remedies.
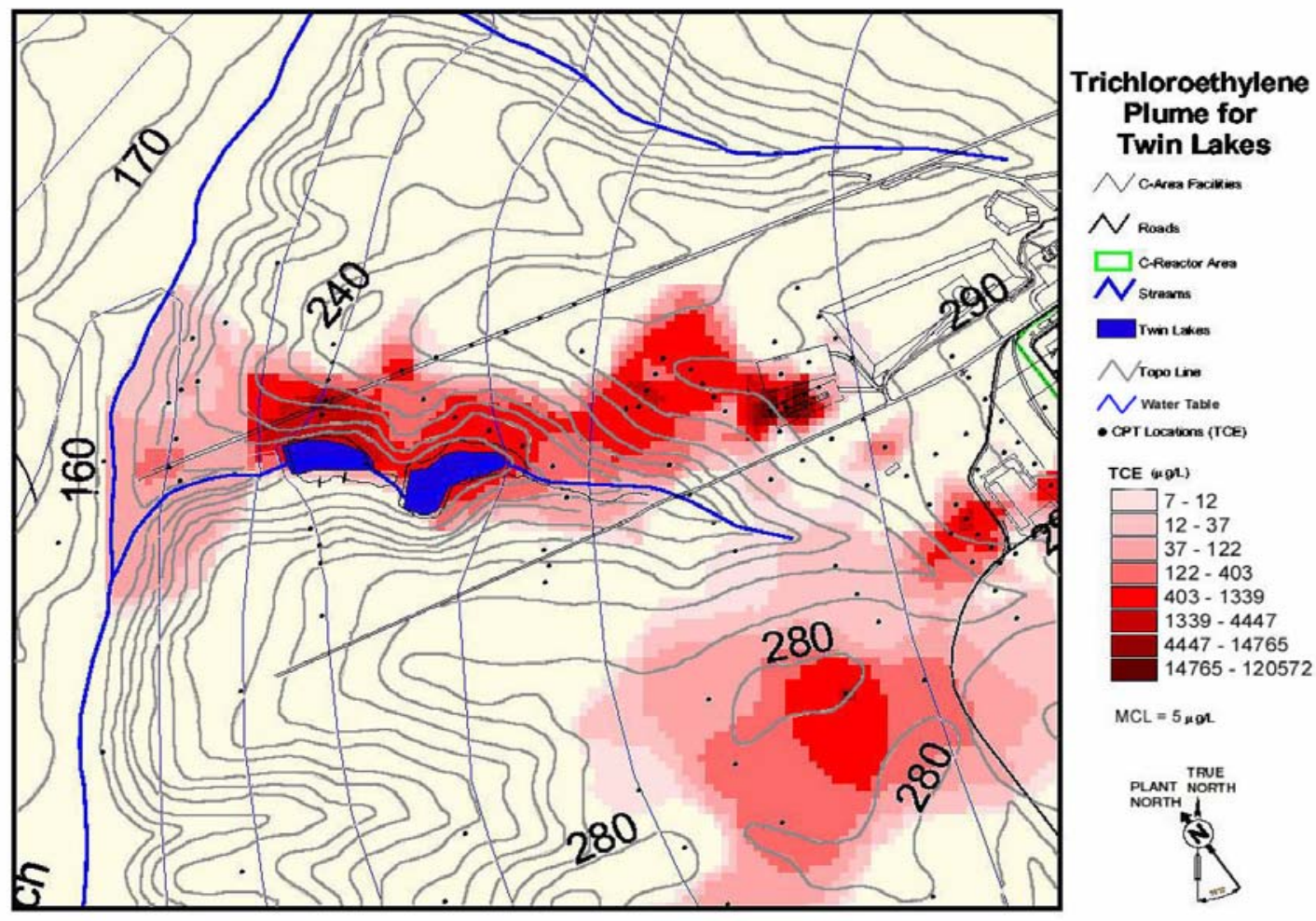

Figure 3.1. Test bed encompassing Twin Lakes and the C-Area Burning/Rubble Pit (Bills et al. 2000).

\subsection{Field Campaign}

Flux monitoring at Twin lakes test bed was conducted over an 18 month period using a network of 14 wells distributed along the longitudinal axis of chlorinated solvent plume originating from CBRP (See Figure 3.2). The monitoring network covered $530 \mathrm{~m}$ or $45 \%$ of the leading longitudinal extent of the plume. Listed in Table 3.1 were relevant characteristics of the 14 wells. The network was comprised of four transects, three oriented transverse and one parallel to the 
WSRC-STI-2006-00315, Rev. 0

December 7, 2006

Page 10 of 31

principal groundwater flow direction. Wells comprising the three transverse transects included CRP40A, CRP40B, CRP45A and CRP45B in the first, CRP43A, CRP43B, and CRP48A in the second, and then CRP44A, CRP44B, CRP49A, and CRP49B in the third. Between the first and second transverse transects were wells CRP41A, CRP41B and CRP42A; these wells comprised the greater longitudinal transect and proved critical in subsequent analyses of flux variations in the direction of groundwater flow. PFMs were deployed for three durations of 8, 42, and 139 days between the months of January 2005 to July 2006. Water levels were measured and groundwater samples were collected from each well prior to PFM installation. Analyses of groundwater samples yielded measurable TCE and DCE concentrations but no VC. Measured well water levels were used to calculate groundwater hydraulic gradients. Fluxmeters were constructed using silver impregnated activated carbon; the preferred PFM sorbent identified in Phase I of the project (Cho, Annable, and Hatfield, 2006). PFMs were exposed to ambient field conditions according to the above stated durations and then retrieved from the wells for sorbent sampling in the field. Three to four samples of activated carbon were collected from each meter. Each sample provided depth-integrated flux measurement corresponding to a $\sim 15 \mathrm{~cm}$ depth interval and three to four samples provided data over the total length of well screen $(\sim 45.7$ to $\sim$ $61 \mathrm{~cm}$ ). Activated carbon samples were analyzed for multiple resident tracers (methanol, ethanol, isopropyl alcohol, tertiary butyl alcohol, and 2,4 dimethyl-3- pentanol) and contaminants TCE, DCE, and VC as described in (Basu et al. 2006; and Annable et al. 2005), Residual resident tracer masses were used to quantify local groundwater fluxes. Estimates of local hydraulic gradients and PFM measured groundwater fluxes were used to quantify local aquifer conductivities (Klammler et al. 2006b). Contaminant masses intercepted and retained by PFMs were used to quantify local contaminant fluxes (Annable et al. 2005; Basu et al. 2006; and Klammler et al. 2006b). 
Table 3.1: Wells in the PFM monitoring network.

\begin{tabular}{|c|c|c|c|c|c|c|c|}
\hline \multicolumn{8}{|c|}{ PFM Monitoring Wells } \\
\hline $\begin{array}{c}\text { Well } \\
\text { Number }\end{array}$ & Well ID & $\begin{array}{c}\text { Screen } \\
\text { Length } \\
{[\mathrm{cm}]}\end{array}$ & $\begin{array}{l}\text { Total } \\
\text { Depth } \\
{[\mathrm{m}]}\end{array}$ & Diameter & $\begin{array}{l}\text { Darcy } \\
\text { Flux } 1 \\
{[\mathrm{~cm} / \mathrm{d}]}\end{array}$ & $\begin{array}{l}\text { Hydraulic } \\
\text { Gradient }^{2}\end{array}$ & $\begin{array}{c}\text { Aquifer } \\
\text { Hydraulic } \\
\text { Conductivity }^{3} \\
{[\mathbf{m} / \mathbf{d}]}\end{array}$ \\
\hline 1 & CRP 45B & 45.7 & 2.95 & 5.4 & 1.4 & 0.012 & 1.2 \\
\hline 2 & CRP 45A & 45.7 & 1.88 & 5.4 & 1.0 & 0.012 & 0.8 \\
\hline 3 & CRP 40A & 61.0 & 3.17 & 5.4 & 1.6 & 0.012 & 1.3 \\
\hline 4 & CRP 40B & 61.0 & 4.09 & 5.4 & 6.0 & 0.012 & 5.0 \\
\hline 5 & CRP 41A & 61.0 & 3.18 & 5.4 & 2.9 & 0.015 & 1.9 \\
\hline 6 & CRP 41B & 61.0 & 3.70 & 5.4 & 3.8 & 0.015 & 2.5 \\
\hline 7 & CRP 42A & 61.0 & 1.74 & 5.4 & 1.7 & 0.018 & 0.9 \\
\hline 8 & CRP 48A & 45.7 & 1.96 & 5.4 & 2.0 & 0.020 & 1.0 \\
\hline 9 & CRP 43A & 61.0 & 2.18 & 5.4 & 1.5 & 0.021 & 0.7 \\
\hline 10 & CRP 43B & 61.0 & 2.90 & 5.4 & 2.4 & 0.021 & 1.2 \\
\hline 11 & CRP 44A & 61.0 & 1.59 & 5.4 & 2.3 & 0.026 & 0.9 \\
\hline 12 & CRP 44B & 57.6 & 2.59 & 5.4 & 2.0 & 0.026 & 0.8 \\
\hline 13 & CRP 49A & 45.7 & 1.55 & 5.4 & 1.3 & 0.026 & 0.5 \\
\hline 14 & CRP 49B & 45.7 & 2.18 & 5.4 & 1.2 & 0.026 & 0.5 \\
\hline
\end{tabular}


WSRC-STI-2006-00315, Rev. 0

November 16, 2006

\subsection{Data Processing}

Page 12 of 31

Water levels, groundwater contaminant concentrations, measured PFM tracers and contaminant masses intercepted and retained on PFMs were used to estimate at each well local groundwater hydraulic gradients, aquifer conductivities, groundwater specific discharge and contaminant mass flux. Illustrated in Figure 3.3 is the flow chart used to process raw data. Requisite raw data appear in red and derived results in blue. Pertinent sections of the report where protocols/methods are discussed are also indicated.

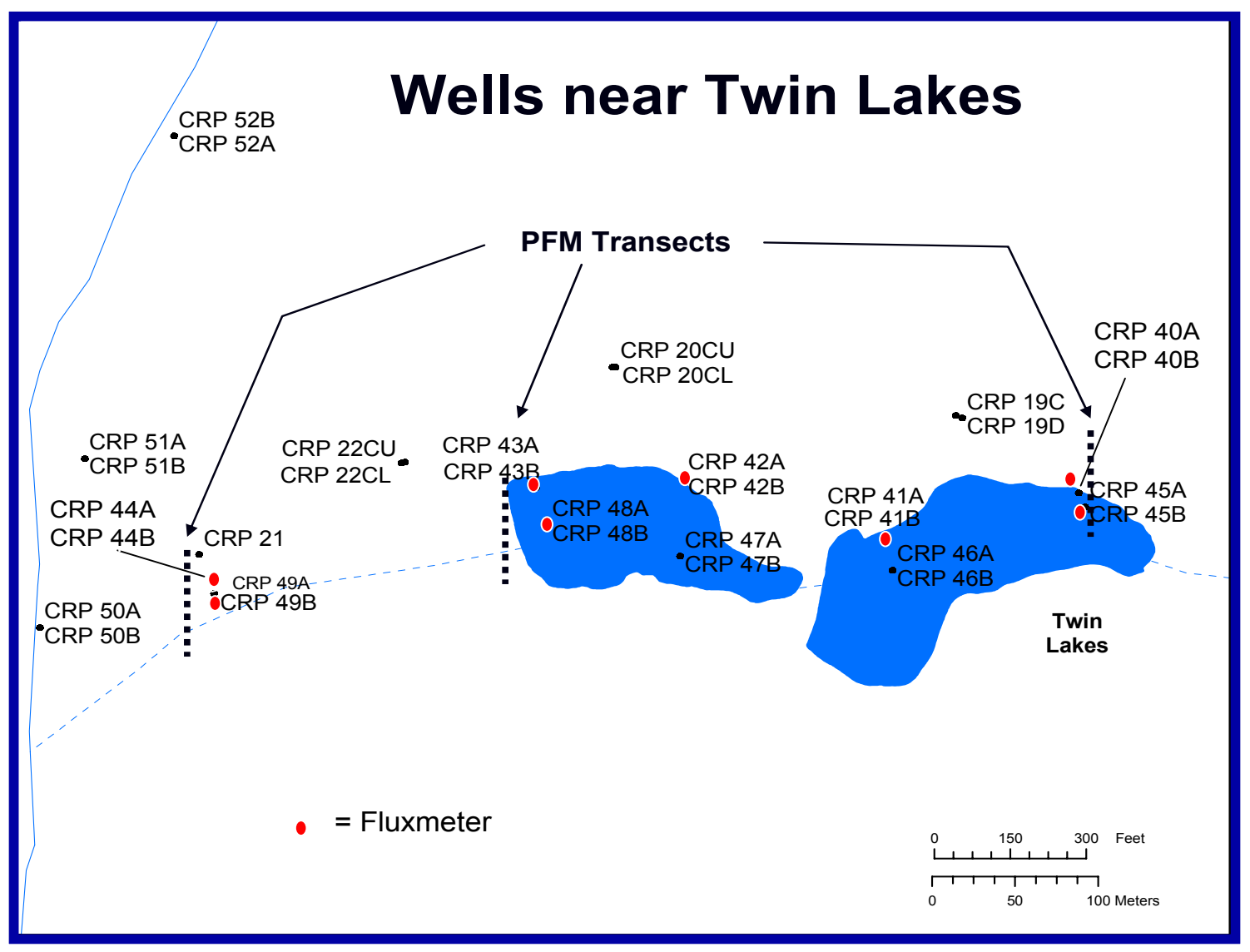

Figure 3.2. Network of 14 wells used for PFM in the test bed encompassing Twin Lakes. 
WSRC-STI-2006-00315, Rev. 0

November 16, 2006

Page 13 of 31

\section{Data Processing}

Contaminant Mass Intercepted by PFM

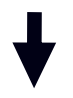

Ambient Contaminant

Mass Flux

(Sections $2.3 \&$ 4.3)

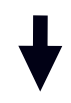

Assessment of Contaminant Attenuation
Residual Mass of Groundwater PFM Tracers

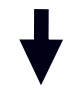

Ambient Ground + Hydraulic Water Flux qo + Gradient

(Sections $2.2 \& 4.1$ ) (Section 4.1)

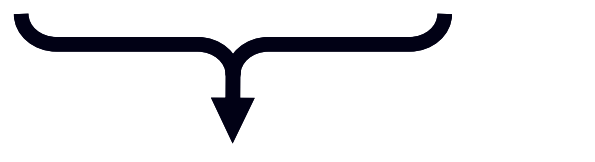

Aquifer Conductivity K (Section 4.2)

Figure 3.3. Data processing flow chart used to generate final results (blue) from raw data (red). 


\subsection{Results}

\subsection{Hydraulic Gradients and Groundwater Fluxes}

Water levels measured on three separate occasions within the 18 month field effort produced similar groundwater elevation profiles. Measured water levels from the field site during the second sampling campaign in September 2005 were plotted in Figure 4.1. For each of the three sampling events, second order polynomials were fitted to describe water elevations as a function of distance along the sampling network $\left(r^{2}=0.99\right)$. Derivatives of these functions were then used to estimate local groundwater gradients at each well location. Changes in water levels were observed between measurements; however, calculated horizontal hydraulic gradients differed by less than 4 percent over the 18 months field effort. Listed in Table 3.1, were average gradients calculated at each well.

Groundwater fluxes were determined as a function of depth at each of the 14 well locations. For these calculations equations 3-5 were used. Following Klammler et al. (2006b), the convergence factor $\alpha$ was equated to 0.88 . Statistics of groundwater flux measurements take during the three PFM deployments were listed in Table 4.1. Due to the similarity in the local horizontal gradients detected over the 18 month field experiment, it was expected that the measured water fluxes at any given well would be similar for each of the three deployments. The average water flux for the site ranged from 2.1 to $2.3 \mathrm{~cm} / \mathrm{d}$ between deployments. Thus, consistent site-wide averages were obtained even though durations of flux monitoring varied by two orders of magnitude. Depth-averaged groundwater specific discharges measured at each well during each of the three deployments were displayed in Figure 4.2. Here again consistent measures were obtained between deployments at most wells except for CRP40B (well No. 4, from Table 3.1) and perhaps CRP44B (well No. 12); here, measurement variations were greater. For each well, calculated discharges obtained from averaging measurements from the three PFM deployments were presented in Table 3.1. Estimated pore water velocities ranged from $2-30 \mathrm{~cm} / \mathrm{d}$ using an effective porosity of $25 \%$ (Flach et al. 1999). 
WSRC-STI-2006-00315, Rev. 0

November 16, 2006

Page 15 of 31

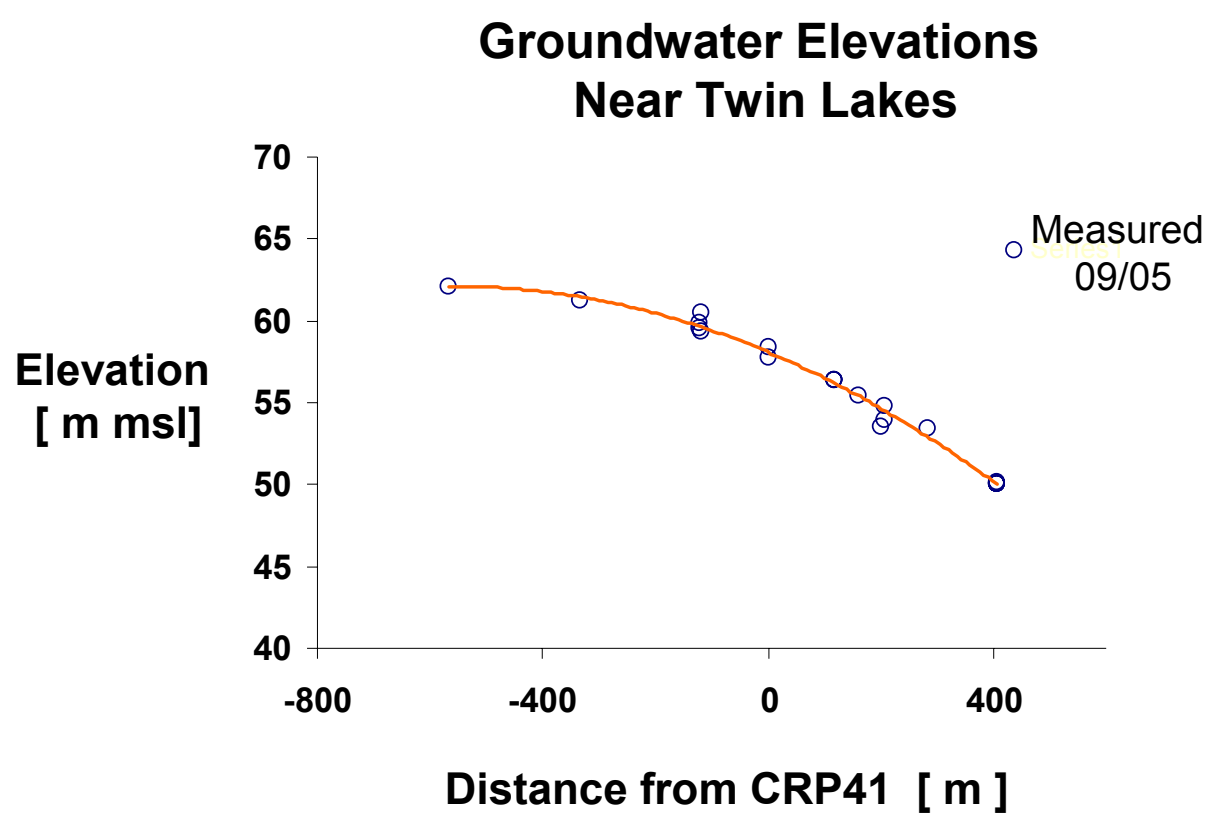

Figure 4.1. Second-order polynomial fit to groundwater elevations measured near Twin Lakes in September 2005. Distance down-gradient from well CRP41 is positive.

Table 4.1: Statistics of PFM measured groundwater specific discharge.

\section{Statistic}

Average

Standard Deviation

Maximum

Minimum

Geometric Mean
Ambient Water Flux [cm/d ] PFM Deployment Duration

$\begin{array}{ccc}8 \text { day } & 42 \text { day } & 139 \text { day } \\ \mathbf{2 . 1} & \mathbf{2 . 3} & \mathbf{2 . 2} \\ \mathbf{1 . 4} & \mathbf{1 . 9} & \mathbf{0 . 9} \\ \mathbf{6 . 5} & \mathbf{7 . 4} & \mathbf{4 . 2} \\ \mathbf{0 . 9} & \mathbf{0 . 6} & \mathbf{1 . 3} \\ \mathbf{1 . 9} & \mathbf{1 . 8} & \mathbf{2 . 0}\end{array}$




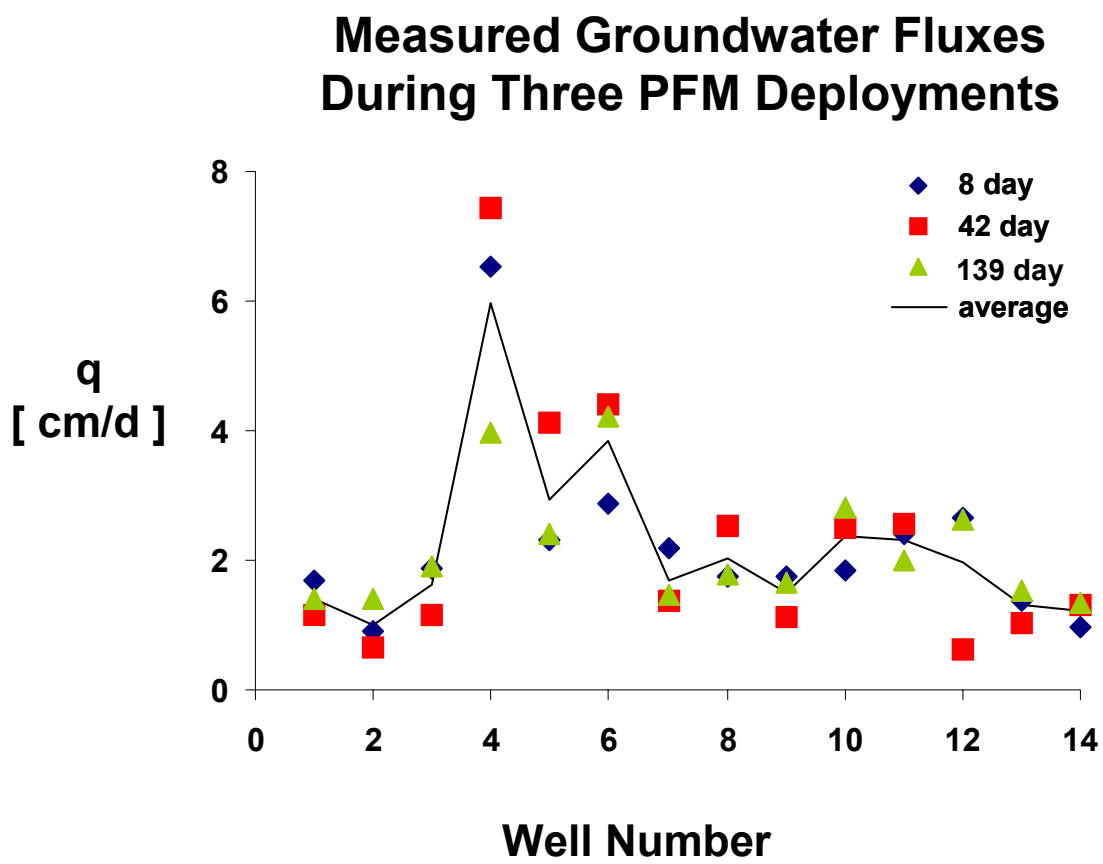

Figure 4.2. PFM measured groundwater specific discharge at each well during each of the three deployments and the simple arithmetic average. Well numbers correspond to those presented in Table 3.1 and matched with labels previously specified.

\subsection{Aquifer Hydraulic Conductivities}

PFM measured groundwater specific discharges and the above described calculated local gradients were used to determine local aquifer conductivities at each well using Darcy's Law.

$$
K=-\frac{q_{O}}{\phi}
$$

where $\mathrm{K}$ is the aquifer hydraulic conductivity $[\mathrm{L} / \mathrm{T}], q_{O}$ is the ambient groundwater flux $[\mathrm{L} / \mathrm{T}]$, and $\phi$ is the local hydraulic gradient [-]. Listed in Table 3.1 were average aquifer conductivities calculated at each well during the field experiment. Additional details and statistics on PFM 
WSRC-STI-2006-00315, Rev. 0

November 16, 2006

Page 17 of 31

estimated conductivities for each deployment period were listed in Table 4.2. Expected results were similar between the different PFM deployment periods. Absolute conductivity values compared closely to the slug test estimates (Flach et al. 1999). Conductivity values reported by Bill et al. (2000) reflected results of large-scale pump tests and as such were not expected to compare with local PFM estimates. A histogram plot of conductivities measured from all wells and all depths (not shown) indicated the chosen increment of depth sampling $(15 \mathrm{~cm})$ was sufficiently small to reveal a conductivity distribution that was positively skewed (i.e., possibly lognormal). Most wells produced consistent determinations of water flux and in turn credible estimates of local aquifer conductivities under quasi-steady hydraulic conditions; hence, it was surmised most PFMs installations were consistent and properly installed. In other words, favorable hydraulic connections were obtained between installed PFMs and the local aquifer such that short-circuiting of groundwater flow through an annulus between the PFM and the aquifer was minimized. This condition must exist to obtain valid measures of both water and contaminant flux.

Table 4.2. Statistics on PFM measured aquifer conductivities.

\section{Aquifer Conductivity Estimates [ $\mathrm{m} / \mathrm{d}$ ]}

$\begin{array}{cccccc}\begin{array}{c}\text { Sampling } \\ \text { Duration }\end{array} & \text { Minimum } & \text { Maximum } & \begin{array}{c}\text { Arithmetic } \\ \text { Mean }\end{array} & \begin{array}{c}\text { Geometric } \\ \text { Mean }\end{array} & \text { Reported } \\ \text { [Days] } & & & \bar{K} & \bar{K}_{G} & \\ \mathbf{8} & \mathbf{0 . 4} & \mathbf{5 . 2} & \mathbf{1 . 3} & \mathbf{1 . 0} & \mathbf{( 1 . 3 - 1 . 4 ) ^ { \mathbf { a } }} \\ \mathbf{4 2} & \mathbf{0 . 3} & \mathbf{7 . 9} & \mathbf{1 . 5} & \mathbf{1 . 0} & \mathbf{( 4 . 0 - 1 0 . 7 ) ^ { \mathbf { b } }}\end{array}$

${ }^{\text {a }}$ Flach et al. 1999

${ }^{\mathrm{b}}$ Bills et al. 2000

\subsection{TCE, DCE, and VC Fluxes}

PFMs were used to obtain direct in situ measures of cumulative TCE, DCE, and VC fluxes in groundwater underlying Twin Lakes. Measurable TCE and DCE fluxes were found in several wells. VC fluxes, however, were quite low $\left(0.25 \mathrm{mg} / \mathrm{m}^{2} / \mathrm{d}\right)$, measured in CRP 44B alone, and then only during the third deployment. From three PFM deployments, a summary of flux statistics were presented in Table 4.3. Average fluxes for TCE and DCE were 3-4 and 1-2 $\mathrm{mg} / \mathrm{m}^{2} / \mathrm{d}$ respectively. TCE fluxes appeared to increase with the sampling duration, but this cannot be confirmed given the large standard errors on estimated means and the positive skewness evident in the distribution of measured fluxes (see Figure 4.3). 
Table 4.3. Statistics of contaminant fluxes from the three PFM deployments.

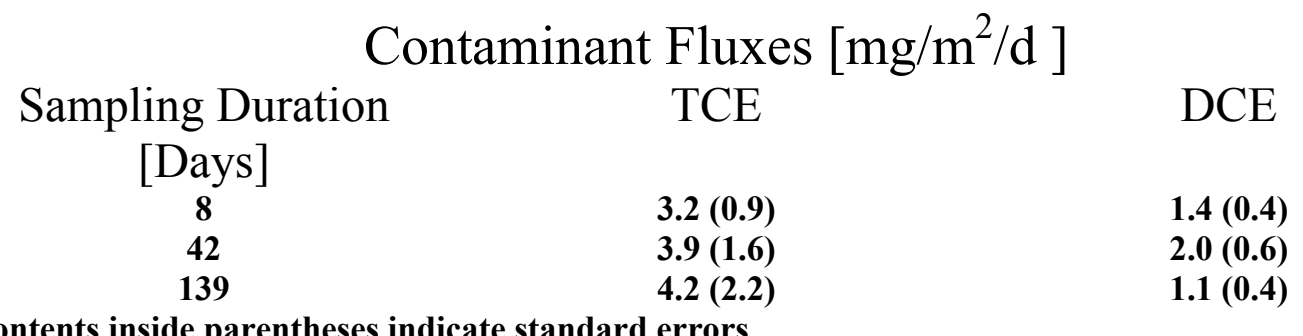

Contents inside parentheses indicate standard errors

\section{Contaminant Flux Histograms}
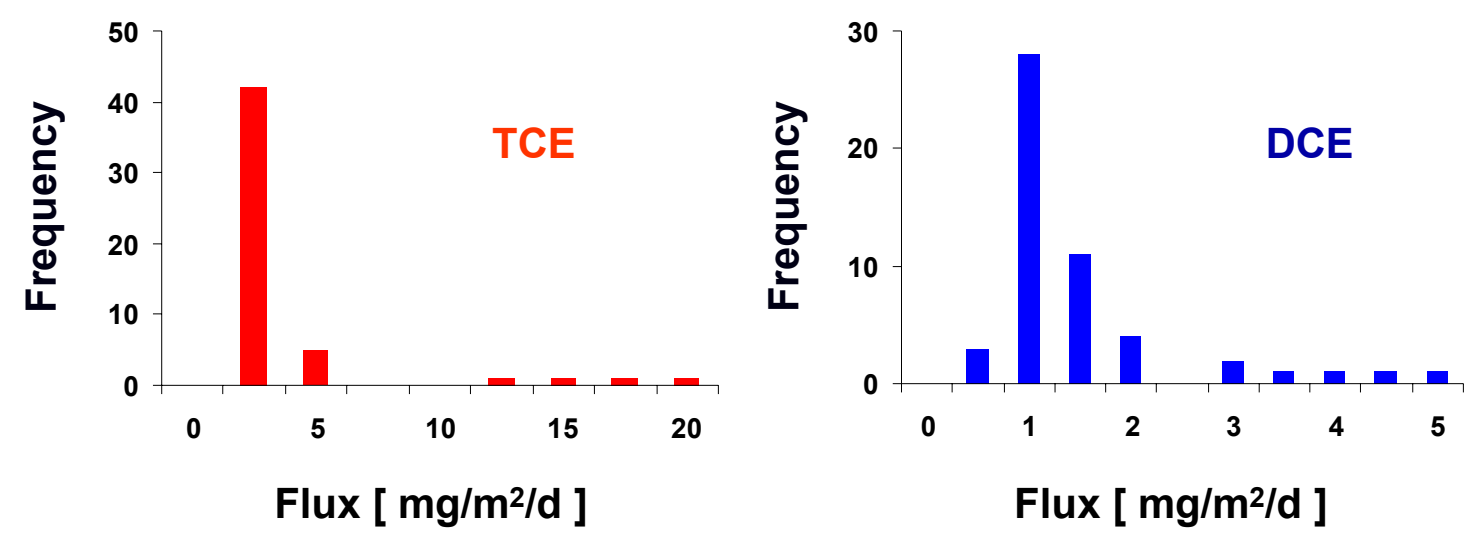

Figure 4.3. TCE and DCE Flux histograms.

Figure 4.4 shows TCE and DCE fluxes vary with depth at wells CRP41A and CRP41B. Both wells are located in the up-gradient portion of the sampling network where TCE fluxes are much greater than DCE. It is also of interest to note that TCE fluxes increase with depth perhaps because the contaminant is a DNAPL and because CRP41A and CRP41B are among the first monitoring wells located down-gradient from the source area and within a groundwater discharge 
WSRC-STI-2006-00315, Rev. 0

November 16, 2006

Page 19 of 31

zone. Flux trends with respect to depth differ between wells but not between seasons or PFM deployments.

Depth-averaged TCE and DCE fluxes were plotted in Figures 4.5 and 4.6. Again measurable VC fluxes were detected in CRP44B alone which was one of the deeper wells located at the downgradient end of the sampling network. For TCE, peak mass flows occurred at well CRP41 and then decreased rapidly within 200 meters in the direction of horizontal groundwater flow. These fluxes were measured over consistent depth intervals of 1.6-4 $\mathrm{m}$ below ground surface and from wells horizontally distributed over a distance of $400 \mathrm{~m}$; thus, it was surmised dispersion, degradation, and possibly volatilization were effecting contaminant attenuation within this thin vertical section of aquifer. Further down-gradient from CRP41A and CRP41B, DCE fluxes increased while TCE decreased significantly. This increase in DCE was due to TCE degradation; however, the rate of increase was less than predicted if DCE were conserved. Plots of molar fluxes for TCE, DCE, and their sum were presented in Figure 4.7. From this figure, it was evident that DCE attenuated at rate similar to TCE; however, at the down-gradient end of the sampling network, DCE attenuation appeared to stall. Using contaminant fluxes from CRP41 as a reference, molar attenuation was approximately $99 \%$ for TCE and $85 \%$ for DCE (this calculation included moles of DCE generated from TCE degradation).

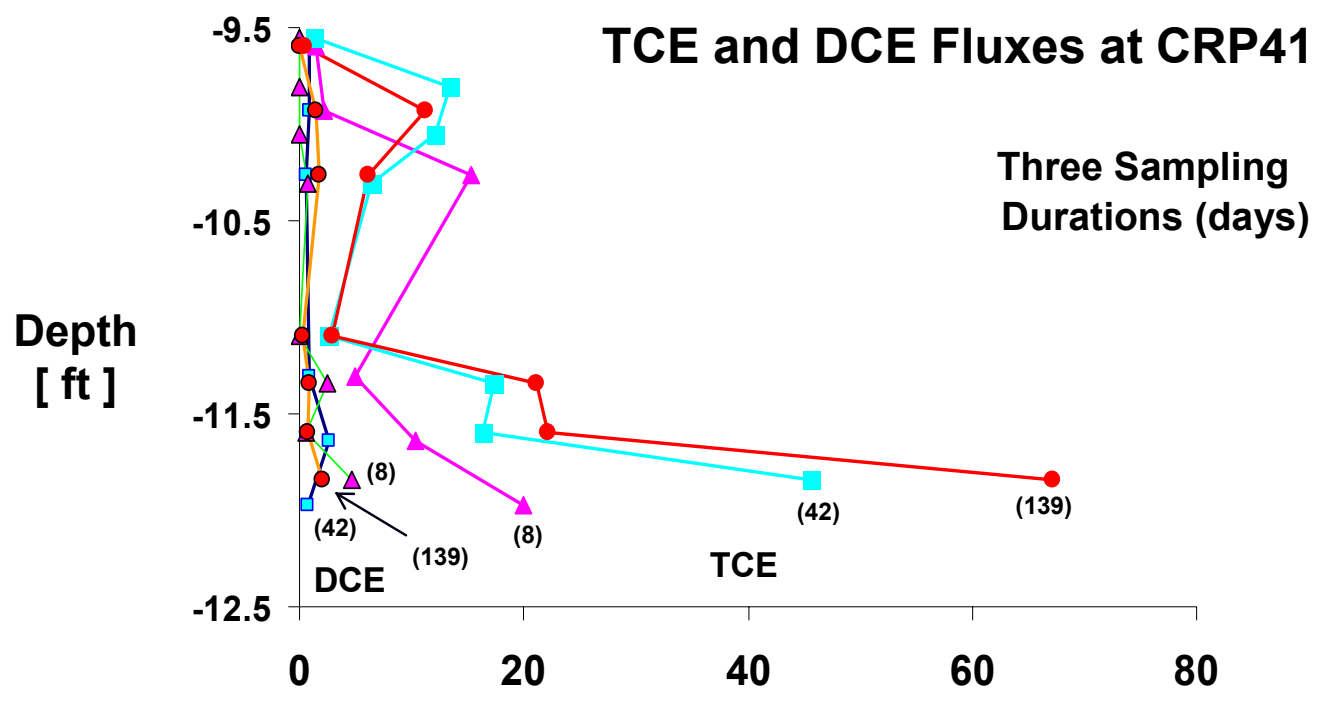

Flux at CRP41 [ mg/m²/d ]

Figure 4.4. Depth variations in measured TCE and DCE fluxes at well CRP41A and CRP41B. 
WSRC-STI-2006-00315, Rev. 0

November 16, 2006

Page 20 of 31

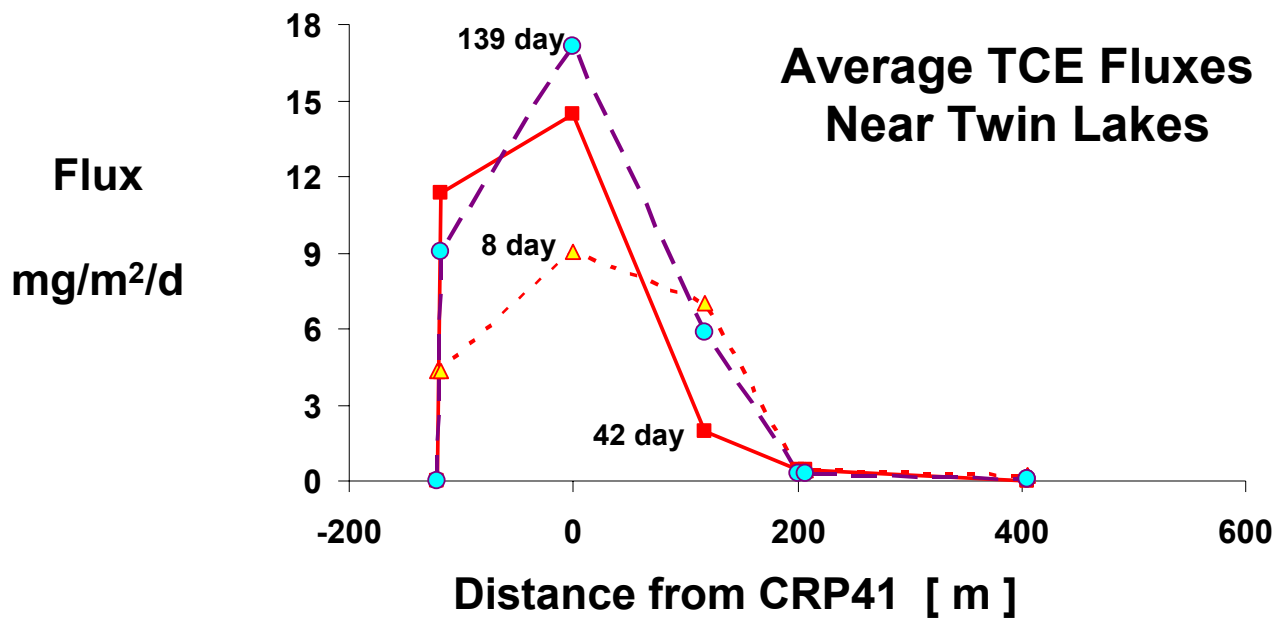

Figure 4.5. TCE fluxes measured in the direction of groundwater flow from three PFM deployment durations.

\section{Average DCE Fluxes Near Twin Lakes}

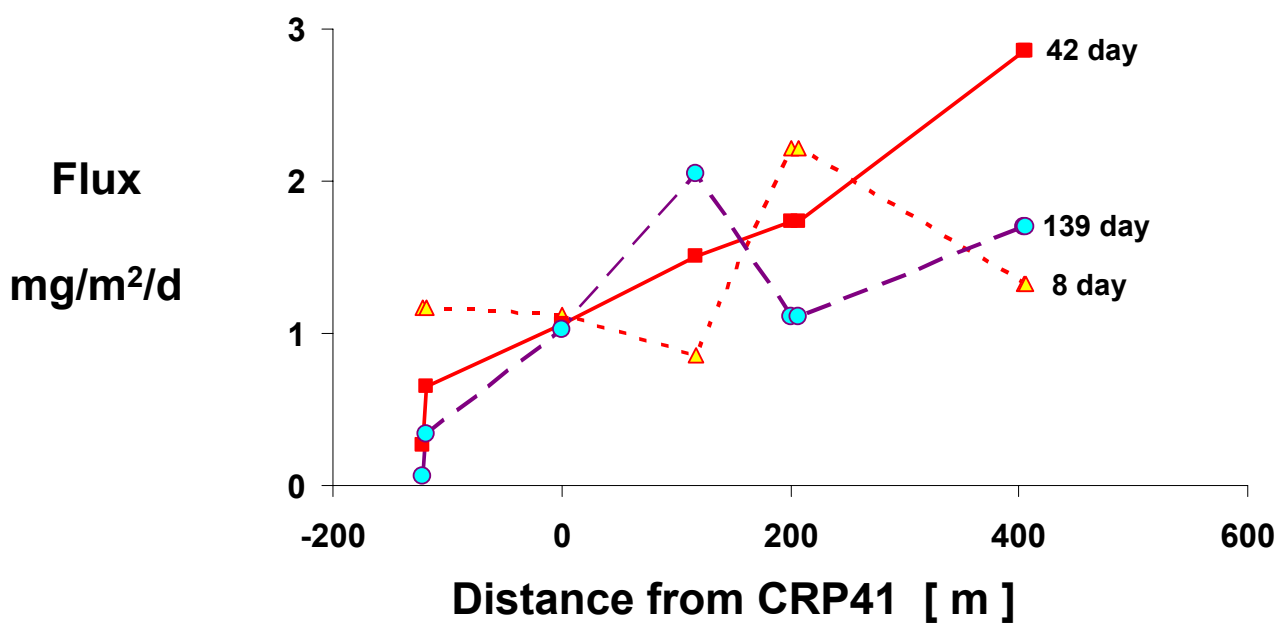

Figure 4.6. DCE fluxes measured in the direction of groundwater flow from three PFM deployment durations. 


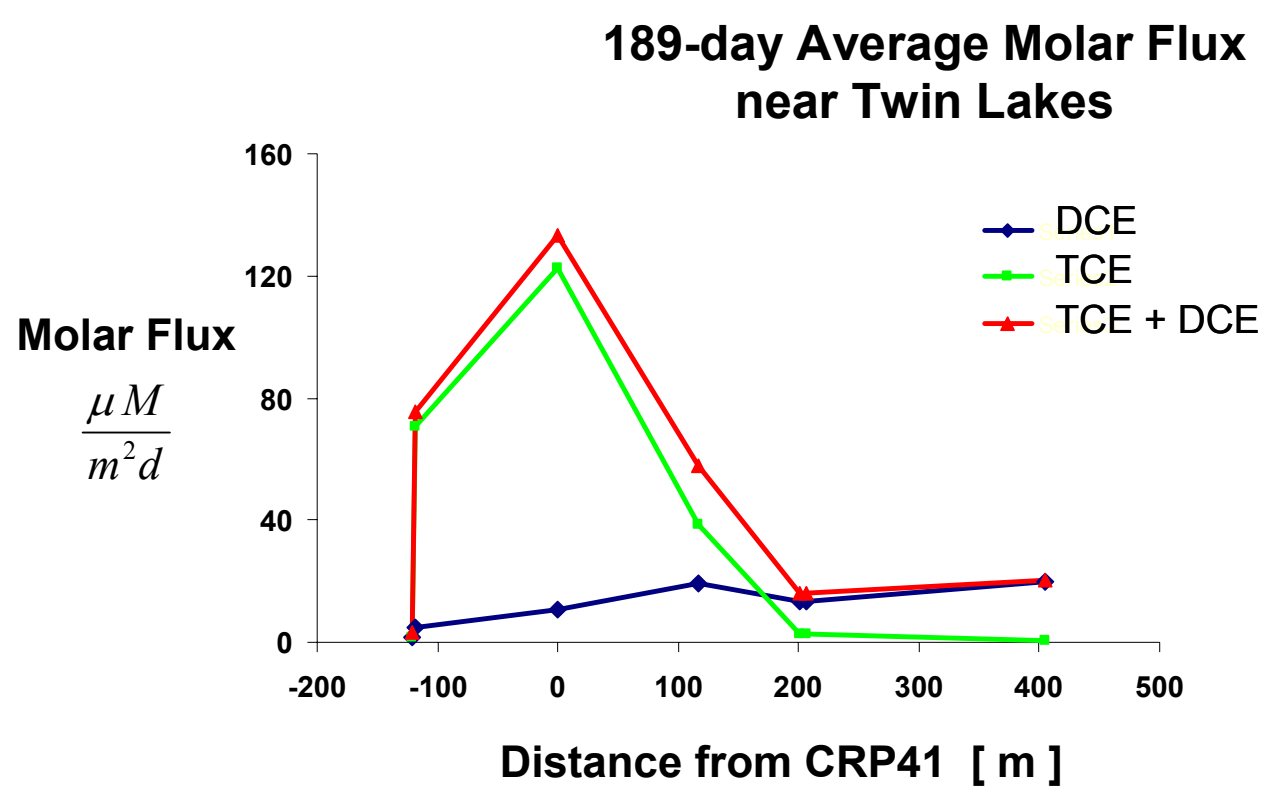

Figure 4.7. 189-day average molar fluxes for TCE, DCE, and their sum.

Given the extended duration of PFM deployments, TCE and DCE degradation on the PFM sorbent was a potential concern. To investigate this potential problem, flux-averaged concentrations, $\mathrm{C}_{\mathrm{F}}$ for TCE and DCE were calculated using PFM data and then compared direct measures of contaminant concentrations in sampled well water. Flux- averaged contaminant concentrations derived from PFMs were obtained from integrating measured water and contaminant fluxes over the screen length.

$$
C_{F}=\frac{\int_{\text {Screen }} J_{C}}{\int_{\text {screen }} q_{O}}
$$


WSRC-STI-2006-00315, Rev. 0

November 16, 2006

Page 22 of 31

Following Basu et al. (2006), these derived concentrations were then compared to contaminant concentrations measured in water samples gathered from each well prior to PFM installation. If the target contaminant were degrading inside the PFM, then the flux-averaged concentration given by PFM should tend to be lower than concentration measured in well. However, the validity of this comparison would dissipate if well water concentrations were not relatively constant over the duration of PFM monitoring.

Plotted in Figure 4.8 are well and PFM flux-averaged concentrations along the sampling network. This figure shows both assessments give comparable concentration distributions over the monitoring network. Plotted well water concentrations reflect the average of three instantaneous measurements taken at each well just before fluxmeters were deployed. Plotted $C_{F}$ values from PFMs represent weighted averages generated from three deployments totaling 189-days of cumulative monitoring.

Because well concentrations varied with time, the comparison given by Figure 4.8 was not conclusive. Thus, more definitive testing would be needed to evaluate contaminant degradation on fluxmeters. Perhaps additional field experiments conducted with PFMs preloaded with fluorinated analogs of TCE, DCE, and vinyl chloride (Vancheeswaran et al. 1999). That is, from measuring the degradation of these analogs on installed PFMs, one could correct ambient measures of TCE, DCE, and VC fluxes for degradation occurring on the PFM sorbent. This information could also serve to generate local assessments of in situ contaminant attenuation resulting from indigenous microbial activity. 
WSRC-STI-2006-00315, Rev. 0

November 16, 2006

Page 23 of 31

\section{Well and PFM Flux-averaged Concentrations} near Twin Lakes

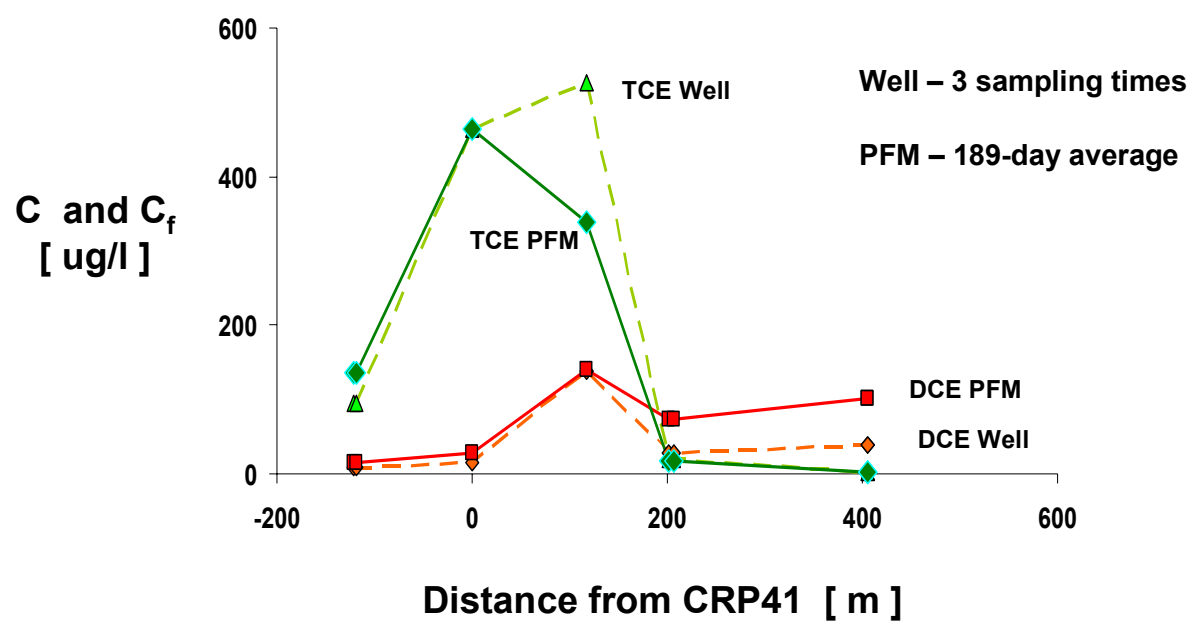

Figure 4.8. Flux-averaged concentrations of TCE and DCE from PFMs compared to groundwater concentrations averaged from three sampling events.

\subsection{Assessment of Natural Attenuation}

One of the stated research objectives was to develop a field-based protocol for determining contaminant loading, contaminant attenuation, and assimilative capacity using spatially distributed flux measurements of target contaminants. In this section, measured contaminant fluxes are used to quantify subsurface contaminant loading and the assimilative capacity of the aquifer within the sampling network. Modeling is then conducted to characterize the rates of TCE and DCE attenuation. Analyses for contaminant loading, assimilative capacity, and attenuation assume the 14 monitoring wells interrogate the same continuous groundwater flow system. Thus, the fate of contaminants measured up-gradient wells is assumed to be appropriately depicted in wells down-gradient. Analyses also assumes measured fluxes at wells CRP41A and CRP41B can be taken as representative TCE and DCE loads to the aquifer underlying Twin Lakes. 
WSRC-STI-2006-00315, Rev. 0

November 16, 2006

Page 24 of 31

Between three PFM deployments, measured contaminant loads ranged from $69-130 \mu \mathrm{M} / \mathrm{m}^{2} / \mathrm{d}$ for TCE and 11-12 uM/m²/d for DCE. Resultant 189-day weighted averages were 123 and 11 $\mu \mathrm{M} / \mathrm{m}^{2} / \mathrm{d}$. Integrated fluxes derived from wells constituting the last transect (i.e., CRP44A, CRP44B, CRP49A, and CRP 49B) were taken to represent TCE, DCE, and VC mass discharges not attenuated within boundaries of the test site. Here the residual contaminant fluxes ranged 0-2 $\mu \mathrm{M} / \mathrm{m}^{2} / \mathrm{d}$ TCE, $14-29 \mu \mathrm{M} / \mathrm{m}^{2} / \mathrm{d}$ DCE and $1 \mu \mathrm{M} / \mathrm{m}^{2} / \mathrm{d}$ VC. The 189 -day average mass flows for contaminants exiting the test site were $0.5,1.0$, and $20 \mu \mathrm{M} / \mathrm{m}^{2} / \mathrm{d}$ for TCE, VC, and DCE respectively.

The composite assimilative capacity of the aquifer to degrade TCE and associated daughter products can be expressed in terms of chloride equivalents or the total moles of free chloride produced when TCE, DCE, and VC are completely degraded. Thus,

$$
\eta=3 J_{T C E}^{I}+2 J_{D C E}^{I}+J_{V C}^{I}-3 J_{T C E}^{O}-2 J_{D C E}^{O}-J_{V C}^{O}
$$

where $\eta$ is the assimilative capacity of the aquifer expressed in molar flux $\left[\mu \mathrm{M} / \mathrm{m}^{2} / \mathrm{T}\right]$ or molar discharge $[\mu \mathrm{M} / \mathrm{T}] ; J_{k}^{i}$ represents the molar flux of contaminant $k$ at the up-gradient end of the sampling network $(i=\mathrm{I})$ or the down-gradient end of the sampling network $(i=\mathrm{O}),\left[\mu \mathrm{M} / \mathrm{m}^{2} / \mathrm{T}\right]$. Coefficients preceding each $J_{k}^{i}$ represent stochiometric coefficients for the moles of chloride produced per mole of contaminant $k$ completely degraded. Using the above stated 189-day average fluxes for TCE, DCE, and VC leaving the test site and the contaminant mass loads measured at wells CRP41A and CRPB, the estimated assimilative capacity of the aquifer was 349 $\mu \mathrm{M} / \mathrm{m}^{2} / \mathrm{d}$ as chloride equivalents. The extent of total contaminant attenuation within the monitored of aquifer can also be determined using the following equation:

$$
\beta_{E}=\frac{3 J_{T C E}^{I}+2 J_{D C E}^{I}+J_{V C}^{I}-3 J_{T C E}^{O}-2 J_{D C E}^{O}-J_{V C}^{O}}{3 J_{T C E}^{I}+2 J_{D C E}^{I}+J_{V C}^{I}}
$$

Where $\beta_{E}$ quantifies the fraction of total contaminant attenuation [-]. Again, using the above stated 189-day average fluxes at wells CRP41A and CRP41B as estimates of contaminant loads to the aquifer and results from the last monitored transect to quantify residual loads, attenuation appears to be $89 \%$ complete. 
WSRC-STI-2006-00315, Rev. 0

November 16, 2006

Page 25 of 31

Modeling was conducted to characterize the rates of TCE and DCE attenuation. Equations 11a and $11 \mathrm{~b}$ below, were adopted to model the system, because they constituted coupled flux-based reactive transport equations that described steady-state convective/dispersive transport and firstorder decay of TCE and DCE in the subsurface.

$$
\begin{aligned}
& \frac{d J_{T C E}}{d x}=\alpha_{L} \frac{d^{2} J_{T C E}}{d x^{2}}-\frac{d J_{T C E}}{d x}-\frac{\varepsilon \lambda_{T C E}}{q_{O}} J_{T C E} \\
& \frac{d J_{D C E}}{d x}=\alpha_{L} \frac{d^{2} J_{D C E}}{d x^{2}}-\frac{d J_{D C E}}{d x}-\frac{\varepsilon \lambda_{D C E}}{q_{O}} J_{D C E}+\frac{\varepsilon \lambda_{T C E}}{q_{O}} J_{T C E}
\end{aligned}
$$

where $J_{T C E}$ and $J_{D C E}$ were convective molar fluxes for TCE and DCE $\left[\mu \mathrm{M} / \mathrm{L}^{2} / \mathrm{T}\right] ; \varepsilon$ was the saturated effective porosity of the aquifer; $\alpha_{L}$ was the longitudinal dispersivity [L]; $\lambda_{T C E}$ and $\lambda_{D C E}$ were first order degradation coefficients for TCE and DCE [1/T]; and $\mathrm{x}$ was the horizontal distance from the source area in the principal direction of groundwater flow [L]. Equations (11a) and (11b) were derived by substituting equation (1) into typical one-dimensional concentrationbased transport equations.

Equations $11 \mathrm{a}$ and $11 \mathrm{~b}$ were solved analytically assuming boundary conditions which specify TCE and DCE fluxes in the near-field match those measured at wells CRP41A and CRP41B and that fluxes in far-field approach zero:

$$
\begin{array}{ll}
\left.J_{T C E}\right|_{x=0}=\left.J_{T C E}\right|_{C P R 41} & \left.J_{T C E}\right|_{x=\infty}=0 \\
\left.J_{D C E}\right|_{x=0}=\left.J_{D C E}\right|_{C P R 41} & \left.J_{D C E}\right|_{x=\infty}=0
\end{array}
$$

Values for decay parameter $\lambda_{T C E}$ and $\lambda_{D C E}$ were determined via model calibration; whereas, parameters representing the groundwater specific discharge $q_{O}$, saturated effective aquifer porosity $\varepsilon$, and longitudinal dispersivity of $\alpha_{L}$, were specified a priori using information from the literature. From Flach et al. (1999) estimated $\varepsilon$ to be 0.25 . The specific discharge $q_{O}$ was equated to the site-wide average of $0.02 \mathrm{~m} / \mathrm{d}$ determined from this study. Finally, following Basu 
WSRC-STI-2006-00315, Rev. 0

November 16, 2006

Page 26 of 31

et al. (2006), the longitudinal dispersivity, $\alpha_{L}$ was specified at $20 \mathrm{~m}$; this represented $5 \%$ of the domain length (i.e., travel distance beyond well CRP41) and 10\% of the total TCE plume length from well CRP41.

From model calibration, best-fit values for $\lambda_{T C E}$ and $\lambda_{D C E}$ were determined to be 0.48 and 0.47 $\mathrm{yr}^{-1}$ respectively. Values of calibrated decay parameters reflected 'effective' or 'apparent' estimates that were greater than those reported by Basu et al. (2006) but well within the range of values (0.1-1 $\left.\mathrm{yr}^{-1}\right)$ reported in the literature (Weidemier et al. 1999). The nature of TCE and DCE degradation was not discerned here, but likely included both aerobic and anaerobic pathways (Basu et al. 2006; Sing et al. 2004; and Davis et a 1. 2002) given the low fluxes of TCE degradation products detected at the site. Model simulated results were displayed in Figure 4.9. The model simulated TCE and DCE fluxes that were comparable to measurements at most locations except for DCE at the down-gradient end of the sampling network. Here it appeared simulations over estimated DCE attenuation. It may be that DCE and VC attenuation had stalled, because low VC fluxes were measured here and nowhere else.

\section{First-order Modeling of TCE and DCE Fluxes}

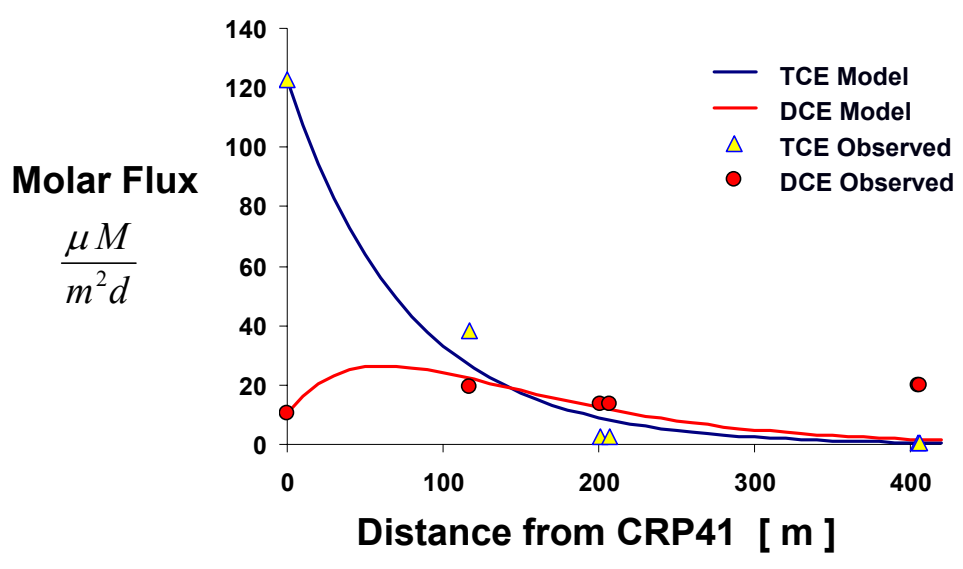

Figure 4.9. First-order modeling of TCE and DCE degradation near Twin Lakes. 
WSRC-STI-2006-00315, Rev. 0

November 16, 2006

Page 27 of 31

\subsection{Conclusions and Recommendations}

This report presents results of a research project in which passive fluxmeters (PFMs) were used to measure changes chlorinated ethene fluxes along the axis of groundwater contaminant plume. This information was used to characterize chlorinated ethene loads and the intensity of natural attenuation. This field-based research project pursued three objectives. The first was to demonstrate an innovative technology for direct in situ measurements of cumulative water and multiple solute fluxes in groundwater. passive fluxmeters were deployed in 14 wells to achieve this objective. The wells were distributed along the longitudinal axis of a chlorinated ethane plume in the Twin Lakes test-bed at the Savannah River Site. At each well location, fluxmeters provided direct and simultaneous measures of TCE, DCE, and VC mass fluxes and groundwater flows. Consistent groundwater and contaminant flux measures were obtained for three different PFM deployment durations. The second and third objectives of the research effort were to develop a field-based protocol for determining contaminant loading, contaminant attenuation, and assimilative capacity using spatially distributed flux measurements of target contaminants and to advance the science and understanding of natural attenuation using measured fluxes. Both objectives were accomplished using simple mass balance models and flux-based contaminant transport models incorporating first-order TCE and DCE attenuation. These transport models were parameterized using measured water flows and contaminant fluxes alone. Typical measures of groundwater levels, aquifer conductivities, and contaminant concentrations were not required.

Results suggested TCE and DCE dilution (dispersion) could not account for degree of flux attenuation determined from measurement taken over the site. Values of calibrated TCE and DCE decay parameters reflected 'effective' or 'apparent' estimates that were greater than those reported by Basu et al. (2006) but well within the range of values $\left(0.1-1 \mathrm{yr}^{-1}\right)$ reported in the literature (Weidemier et al. 1999). Using the above stated 189-day average fluxes at wells CRP41A and CRP41B as estimates of contaminant loads to the aquifer and results from the last monitored transect to quantify residual loads, attenuation appears to be $89 \%$ complete. The nature of TCE and DCE degradation was not discerned here, but likely included both aerobic and anaerobic pathways (Basu et al. 2006; Sing et al. 2004; and Davis et a 1. 2002) given the low fluxes of TCE degradation products detected at the site. 
WSRC-STI-2006-00315, Rev. 0

November 16, 2006

Page 28 of 31

Given the extended duration of PFM deployments, TCE and DCE degradation on the PFM sorbent is a concern. To investigate this potential problem, it is recommended that additional field experiments be conducted with PFMs preloaded with fluorinated analogs of TCE, DCE, and vinyl chloride. If it is observed that these analogs degraded on installed PFMs, one can then correct ambient measures of TCE, DCE, and VC fluxes for degradation occurring on the PFM sorbent. It is also recommended that research be conducted to determine if the observed degradation of these analogue PFMs can be used to generate local assessments of in situ contaminant attenuation resulting from indigenous microbial activity. In addition, a simultaneous analysis of PFM sorbent samples using available molecular/biological tools is likely to shed considerable insight on the organisms effecting both tracer and contaminant attenuation. 


\section{WSRC-STI-2006-00315, Rev. 0 \\ November 16, 2006 \\ Page 29 of 31}

\subsection{References}

Aadland, R.K., J.A. Gellici, P.A. Thayer. 1995. Hydrogeologic Framwork of West Central South Carolina. Report 5, Water Resources Division, South Carolina Department of Natural Resources, Columbia. SC.

Aadland, R.K., M.K. Harris, C.M. Lewis, T.F. Gaughan, and T.M. Westbrook. 1991. Hydrostratigraphy of the General Separations Area, Savannah River Site (SRS), South Carolina. WSRC-RP-91-13, Westinghouse Savannah River Company, Aiken, SC 29808.

Annable, M.D., K. Hatfield, J. Cho, H. Klammler, B. Parker, J. Cherry, and P.S.C. Rao. 2005. Field-scale evaluation of the passive flux meter for simultaneous measurement of groundwater and contaminant fluxes. Environmental Science and Technology, 39 (18), 7194 -7201.

Basu, N., P.S.C. Rao, I.C. Poyer, M.D. Annable, and K. Hatfield, 2006. Flux-based assessment at a manufacturing site contaminate with trichloroethylene. Journal of Contaminant Hydrology 86 (1-2), 105-127.

Bayer-Raich, M., J. Jarsjo, R. Liedl, T. Ptak, and G. Teutsch. 2006. Integral pumping test analyses of linearly sorbed groundwater contaminants using multiple wells: Inferring mass flows and natural attenuation rates, Water Resources Research 42 (8), Art No. W08411.

Bills, T.L., K.E. Brewer, A.L. Stieve, M.S. Rabin. 2000. Groundwater Flow Modeling for C-Area Groundwater operable unit (U). WSRC-RP-2000-4096. Westinghouse Savannah River Company LLC, Savannah River Site, Aiken, SC 29808

Bockelmann, A., Ptak, T., Teutsch, G., 2001. An analytical quantification of mass fluxes and natural attenuation rate constants at a former gasworks site. J. Contam. Hydrol., 53, 429-453.

Bockelmann, A., Zamfirescu, D., Ptak, T., Grathwohl, P., and Teutsch, G., 2003. Quantification of mass fluxes and natural attenuation rates at an industrial site with a limited monitoring network: a case study. J. Contam. Hydrol., 60, 97-121.

Borden, R.C., Daniel, R.A., LeBrun IV, L.E., Davis, C.W., 1997. Intrinsic biodegradation of MTBE and BTEX in a gasoline-contaminated aquifer. Water Resour. Res. 33 (5), 1105-1115.

Campbell, T. J., K. Hatfield, H. Klammler, M. D. Annable, and P.S.C. Rao. 2006. Magnitude and directional measures of water and $\mathrm{Cr}(\mathrm{VI})$ fluxes by passive flux meter. Environmental Science and Technology, 40, 6392-6397.

Cho, J., M.D. Annable, K. Hatfield. 2006. Sorbent Selection for Passive Fluxmeter Applications at the Twin Lakes Site, Savannah River National Laboratory (In press).

Davis, J.W., J.M. Odom, K.A. DeWeerd, D.A. Stahl, S.S. Fishbain, R.J. West, G.M. Klecka, and J.G. DeCarolis. 2002. "Natural attenuation of chlorinated solvents at Area ^, Dover Air Force Base: characterization of microbial community structure.” J. of Contam. Hydrol., 57, 41-59.

Flach, G.P., M.K. Harris, R.A. Hiergesell, A.D. Smits, and K.L. Hawkins. 1999. Hydrogeological Analysis and Groundwater Flow for C-Reactor Area with Contaminant Transport for C-Reactor 
Seepage Basins (CRSB) and C-Area Burning/Rubble Pit (CBRP)(U). WSRC-TR-99-00310, Westinghouse Savannah River Company LLC, Savannah River Site, Aiken, SC 29808.

Hatfield, K., Rao, P.S.C., Annable M.D., and Campbell T., 2002a. Device and method for measuring fluid and solute fluxes in flow systems, Patent US 6,402,547 B1.

Hatfield, K. M.D. Annable, S. Kuhn, P.S.C. Rao, and T. Campbell. 2002b. “A New Method for Quantifying Contaminant Flux at Hazardous Waste Sites," Groundwater Quality 2001, IAHS Publication 275Red Book, Sheffield United Kingdom, pp. 25-32.

Hatfield, K., M. Annable, J. Cho, P.S.C. Rao, and H. Klammler. 2004. “A Direct Method for Measuring Water and Contaminant Fluxes in Porous Media," Contaminant Hydrology (In Press),

Holder, Th., Teutsch, G., Ptak, T., and Schwarz, R., 1998. A new approach for source zone characterization: the Neckar Vally study. In: M. Herbert and K. Kovar (Eds.), Groundwater Quality: Remediation and Protection. IAHS Publication No. 250, IAHS Press, Oxfordshire, OX10 8BB, United Kingdom, pp. 49-55.

Kao, C.M. and Wang, Y.S., 2001. Field investigation of natural attenuation and intrinsic biodegradation rates at an underground storage tank site. Environ. Geol. 40 (4-5), 622-631.

King, M.W.G., Barker, J.F., Devlin, J.T., and Butler, B.J., 1999. Migration and natural fate of a coal tar cresote plume: 2. Mass balance and biodegradation indicators. J. Contam. Hydrol. 39, 281-307.

Klammler, H., K. Hatfield, and M. Annable. 2006a. Concepts for measuring horizontal groundwater flow directions using the passive flux meters. Advances in Water Resources (In press).

Klammler, H., K. Hatfield, M. Annable, E. Agyei, B. Parker, J. Cherry, and P.S.C. Rao. 2006b. General analytical treatment of the flow field relevant for passive fluxmeter interpretation. Water Resources Research (In Press).

Kubert, M. and Finkel M. Contaminant mass discharge estimation in groundwater based on mult-level point measurements: A numerical evaluation of expected errors. J. Contam. Hydrol. 2006;84:55-80.

Schwarz, R., Ptak, T., Holder, Th., and Teutsch, G., 1998. Groundwater risk assessment at contaminated sites: a new approach for the inversion of contaminant concentration data measured at pumping wells. In: M. Herbert and K. Kovar (Eds.), Groundwater Quality: Remediation and Protection. IAHS Publication No. 250, IAHS Press, Oxfordshire, OX10 8BB, United Kingdom, pp. 68-71.

Sing, H., F.E. Loffler, and B.Z. Fathepure,. 2004. "Aerobic biodegradation of vinyl chloride by a highly enriched mixed culture." Biodegradation, 1-8.

Teutsch, G., Ptak, T., Schwarz, R., Holder, T., 2000. Ein neues integrals Verfahren zur Quantifizierung der Grundwasserimmission. Teil I: Breschreibung der Grundlagen. Grundwasser $4(5), 170-175$. 
WSRC-STI-2006-00315, Rev. 0

November 16, 2006

Page 31 of 31

USEPA, 1998. Technical Protocol for Evaluating Natural Attenuation of Chlorinated Solvents in Ground Water, EPA/600/R-98/128, September.

Vancheeswaran, S., M. Hyman, and L. Semprini. 1999. "Anerobic biotransformation of trichloroflouroethene in groundwater microcosms," Environ. Sci. Technol. 33, 2040-2045.

Wiedemeier, T.D., H.S. Rifai, C.J. Newell, and J.T. Wilson. 1999. Natural attenuation of fuels and chlorinated solvents in the subsurface. John Wiley and Sons, Inc. New York, NY. 